\title{
El procedimiento legislativo descentralizado en Italia y España
}

Francisco Fernández Segado

\section{Introducción: el nuevo rol de las Comisiones en el marco del Parla- mento del Estado social democrático de derecho}

Las Comisiones parlamentarias, según la clásica definición de Barthélemy, ${ }^{1}$ son órganos constituidos en cada Cámara, compuestos de un número por lo general limitado de sus miembros, elegidos sobre la base de una presumible competencia y están encargados, en principio, de preparar su trabajo normalmente mediante la presentación de dictámenes. ${ }^{2}$ Es claro, pues, el carácter auxiliar de la Cámara que en esta definición presentan las Comisiones y que el propio autor proyectaría hacia las tres grandes funciones que cumplen los Parlamentos: la función legislativa, la de control y la presupuestaria.

Ha sido, sin embargo, en relación con la función legislativa donde en mayor medida se ha fundamentado la existencia de las Comisiones parlamentarias que, como bien se ha significado ${ }^{3}$, lejos de perder su fuerza, ésta no ha hecho más que afirmarse en el curso de los dos últimos siglos, y de modo muy particular en el pasado siglo XX, y ello, de un lado, por el crecimiento imparable de la legislación, y de otro, por el carácter cada vez más tecnicista de la misma.

1 Joseph Barthélemy: "Essai sur le travail parlementaire et le système des commissions", Librairie Delagrave, París, 1934, p. 10.

2 Ibidem, p. 212.

3 Pierre Pactet: "Les Commissions parlementaives", en Revue du Droit Public et de la Science Politique, soixantième année, Paris, 1954, p. 127 y ss.; en particular, p. 128. 
La organización parlamentaria en Comisiones, aun siendo un fenómeno común, ha ofrecido manifestaciones diferenciadas según las épocas y los países, distinguiéndose al respecto dos grandes sistemas de organización parlamentaria en Comisiones: el sistema de Comisiones no permanentes ni especializadas del Parlamento inglés y el sistema de las Comisiones permanentes y especializadas del Congreso norteamericano. En otros países, como es el caso francés, la riqueza y variedad de textos constitucionales ha sido tal, que ha posibilitado la aplicación en determinados momentos históricos de la mayor parte de las fórmulas posibles $^{4}$, presentándosenos Francia en éste, como en otros ámbitos, como auténtico laboratorio Constitucional.

El sistema de las Comisiones parlamentarias, al sustraer a las Cámaras en Pleno la siempre larga y compleja tarea de proceder directamente al examen y deliberación de los proyectos legislativos, vino a aligerar de modo notable el trabajo parlamentario, mostrándose desde esta óptica como enormemente funcional. Pero la modesta labor originariamente asumida por las Comisiones, ha ido en la práctica, con el devenir del tiempo, alcanzando un nivel tal que ha propiciado la incidencia frontal de las Comisiones en las relaciones entre el poder legislativo y el poder ejecutivo. Como en esta dirección subraya D'Eufemia ${ }^{6}$, el aspecto de mayor interés de la institución constitucional de las Comisiones parlamentarias es que éstas, de simples órganos de estudio y delegación temporal encargadas de preparar la obra legislativa, se han transformado en los ordenamientos que las admiten constitucional, reglamentaria o

4 Dimitri-Georges Lavroff: "Les Commissions de l'Assemblée Nationale sous la Ve Répúbliquen, en Revue du Droit Public et de la Science Politique, 1971, núm. 6, noviembre-diciembre 1971, p. 1429 y ss.; en concreto, p. 1432.

5 Las oscilaciones del rol de las Comisiones en la historia constitucional francesa son notables, encontrando sus polos extremos, en lo que hace a la intervención de las Comisiones en el trabajo legislativo, en el Senado-consulto orgánico del 28 Frimario del año XIl (18 de mayo de 1804), que opta por la interdicción de cualquier intervención de las Comisiones, y en la Constitución de la Cuarta República, de 27 de octubre de 1946, que se decanta por la libertad más absoluta de tales órganos, Cfr. al efecto, Paul Cahoua: "Les commissions, lien du travail législatif", en Ponvoirs, núm. 34 (monográfico sobre "L'Assemblée"), París, 1985, p. 37 y ss.

6 Giuseppe D’Eufemia: “Le Commissioni palamentani nelle Costituzioni modeme», en Revista Trimestrale di Diritto Pubblico, año VI, núm. 1, enero-marzo 1956, p. 16 y ss.; en particular, pp. 18-19. 
consuetudinariamente, en órganos permanentes y autónomos que vienen a alterar o incidir de hecho en el sistema de relaciones entre los poderes constitucionalmente establecidos.

Esta mutación del rol funcional de las Comisiones es inexplicable al margen del profundo proceso de transformación que ha experimentado el Estado liberal de derecho del siglo XIX y que ha conducido al Estado social y democrático de derecho de nuestros días. Mientras el primero se limitaba a garantizar a los ciudadanos la integridad de la esfera de su autonomía personal, el segundo se ha propuesto llevar a cabo una redistribución de la riqueza presidida por los principios materiales de igualdad y justicia, lo que se ha traducido de inmediato en una notabilísima ampliación de las tareas administrativas y, desde luego, también de las legislativas.

Estas profundas mutaciones han llevado consigo, a su vez, un cambio no menos radical en el concepto tradicional de la ley. Mientras que en coherencia con la concepción originaria de la ley como garantía y medida de la libertad civil y expresión de la voluntad general, el ideal se cifra, como señala Diez Picazo ${ }^{7}$, en pocas leyes y claras, nociones estrechamente unidas, que se presuponen, pues la claridad es necesaria consecuencia de la escasez, ese esquema perfectamente nítido y coherente entra en crisis cuando el Estado social de derecho ha de hacer frente a múltiples funciones en ámbitos tan diferentes y tan alejados de los propios del Estado liberal como el económico, el social y el cultural, por sólo citar los más característicos. A partir de ese momento comienzan a surgir, como de nuevo señala Diez Picazo ${ }^{8}$, formas aberrantes de leyes como es el caso de las denominadas «leyes medida», que son leyes singulares enderezadas a resolver un problema concreto o a adoptar medidas de situación o de conyuntura, leyes, en definitiva, sin ninguna pretensión de perennidad.

La quiebra de la vocación de intemporalidad o perennidad de la ley, fruto de la propia coyunturalidad de muchas de ellas, y el hecho irrefutable de la cada vez mayor promiscuidad de las leyes singulares ${ }^{9}$, que

7 Luis Diez Picazo, "Constitución, Ley, Juez", en Revista Española de Derecho Constitucional, núm. 15, setiembre-diciembre 1985, p. 9 y ss.; en concreto, p. 10.

8 Ibidem, p. 11.

9 Como señala Santamaría, las leyes singulares en sentido estricto no pueden considerarse inadmisibles en el actual Estado de Derecho, pues aún siendo un carácter 
constituyen un instrumento casi imprescindible en un estado con vocación claramente administrativa, tienen como consecuencia la multiplicación del número de leyes que han de aprobar los Parlamentos. Si a esta hiperinflación legislativa se añade el carácter tecnocrático de buen número de textos altamente especializados, se puede comprender el profundo impacto que la nueva situación había por fuerza de tener sobre el procedimiento legislativo, y no sólo desde luego sobre él.

Consecuencia de todo ello ha sido, de un lado la asunción por el Ejecutivo de un rol cada vez más destacado en la función legislativa, de lo que da prueba el cada vez más frecuente recurso a la técnica de la delegación legislativa en el Gobierno o el empleo frecuente por éste de los decretosleyes o decretos de urgencia, según las diversas denominaciones acuñadas. Y de otro lado, el sometimiento del procedimiento legislativo a mecanismos racionalizadores que se imbrican en el más amplio fenómeno de racionalización general de todos los procedimientos que, como se ha advertido $^{10}$, preña la vida parlamentaria en la actualidad, con el objetivo común de producir el máximo de funcionalidad al sistema político o, si se prefiere, de ofrecer el máximo de confortabilidad política al órgano motor y responsable de la política nacional, el Gobierno.

La mayor articulación de los procedimientos legislativos que se puede apreciar en los ordenamientos contemporáneos va estrechamente unida a la aparición, en ocasiones, de nuevos centros de decisión jurídicamente relevantes en el curso del procedimiento legislativo, fenómeno que Cervati ${ }^{11}$ vincula a la creciente complejidad social y a la dificultad de articular los intereses en contraste. Y entre esos centros, en algunos países como Italia y España, ninguno tan relevante como las Comisiones parlamentarias, que de ser órganos de trabajo, auxiliares de los ple-

"natural", la generalidad ya no es un rasgo esencial de la ley. Juan Alfonso Santamaría Pastor: Fundamento de Derecho Administrativo, vol. 1, Editorial Centro de Estudios Ramón Areces, Madrid, 1991, p. 528.

10 Juan Luis Paniagua Soto: «El sistema de Comisiones en el Parlamento español", en Revista de la Facultad de Derecho de la Universidad Complutense, núm. 10 (monográfico sobre "Estudios de Derecho Parlamentario»), Madrid, 1986, p. $111 \mathrm{y}$ ss.; en concreto, p. 111.

11 Angelo Antonio Cervati: Comentario al artículo $72^{\circ}$ ", en A.A. V.V. Cervati y Giovanni Grotanelli, "La formazione delle leggi", tomo I, vol. 1, en "Commentario della Costituzione» (A cura di Giuseppe Branca), Zanichelli Editore-II Foro Italiano, BolognaRoma, 1985, p. 108 y ss.; en particular, p. 183. 
nos de las Cámaras, han pasado a convertirse en órganos decisorios, por mor de la entronización Constitucional del que Mortati, en la Asamblea Consituyente italiana, la llamara procedimiento descentralizado (procedimento decentrato). ${ }^{12}$

En efecto, el Art. $72^{\circ}$ de la Constitución italiana, uno de los más controvertidos de la Norma suprema del país transalpino, tras establecer en el primero de sus párrafos el procedimiento normal de examen y aprobación de todo proyecto de ley ( ogni disegno di legge») presentado a una de las Cámaras: será examinado, según lo que disponga el reglamento respectivo, por una Comisión y luego por la propia Cámara (esto es, por su pleno), que lo aprobará artículo por artículo y en una votación final, y habilitar, en el segundo párrafo, a los Reglamentos de cada Cámara para que establezcan procedimientos abreviados para los proyectos de ley que se declaren urgentes, regula en el párrafo tercero el procedimiento descentralizado en los siguientes términos:

«Podrá asimismo disponer (el Reglamento de cada Cámara) en qué casos y de qué forma procede trasladar el examen y la aprobación de los proyectos de ley a las Comisiones, incluso a las permanentes, compuestas de modo tal que reflejen las proporciones de los grupos parlamentarios. También en tales casos, hasta el momento de su aprobación definitiva, el proyecto será reenviado al Pleno de la Cámara si el Gobierno, una décima parte de los componentes de la Cámara o una quinta parte de la Comisión reclaman que sea discutido y votado por la Cámara misma o bien que sea sometido a la aprobación final de ésta únicamente con declaraciones de voto ("con sole dichiarazioni di voto»). El Reglamento determinará la forma de publicidad de los trabajos de las Comisiones».

Se establece así, frente al rol tradicional de las Comisiones parlamentarias consagrado en el párrafo primero del precepto (lo que los italianos llaman "commissioni in sede referente»), una singularidad ("commissioni in sede deliberante") que, pensada inicialmente como una excepción frente

12 Mortati, en "Atti Assemblea Costituente», p. 1195. Sesión del 14 de octubre de 1947. Cit. por Franco Pierandrei: "Les Commissions Législatives du Parlement Italien", en Revue Française de Science Politique, vol, II, núm. 3, julio-septiembre 1952. p. 557 y ss.; en concreto, p. 558, nota 2. El mismo trabajo publicado en italiano en "Il Foro Padano", año VII, núms. 7-8, julio-agosto 1952, p. 74 y ss.; en concreto, p. 74, nota 2. 
a la regla procedimental general, se ha convertido en la praxis, en la regla casi constante para buena parte de la legislación parlamentaria, con efectos diversamente valorados, pero, como advierte la doctrina ${ }^{13}$, no ciertamente desechables, bien sobre la calidad de la producción legislativa, por cuanto que parece fuera de toda duda que la legislación de comisión ha contribuido a la proliferación de las llamadas despectivamente "leggine» (leyecillas), bien sobre la relación entre mayoría y oposición parlamentarias, especialmente si se advierte el poder de la minoría de solicitar el reenvío al pleno de la Cámara del proyecto legislativo ya asignado a la Comisión deliberante y las relevantes consecuencias que tal poder entraña en la praxis parlamentaria.

El Art. $72^{\circ}$ se completa con un último párrafo que consagra la llamada reserva de ley de Pleno ("riserva di legge d'Assemblea»), excluyendo del análisis por la Comisión en sede deliberante determinados proyectos de ley. A tenor del mismo:

«Se adoptará siempre el procedimiento normal de examen y aprobación directa por el Pleno para los proyectos de ley en materia constitucional y electoral y para los de delegación legislativa, de autorización para ratificar tratados internacionales, de aprobación de presupuestos y cuentas».

\section{El procedimiento legislativo descentralizado en la Constitución es- pañola. Sus antecedentes.}

I. El Art. $75^{\circ}$ de la Constitución española de 1978 , tras disponer en su apartado primero que «las Cámaras funcionarán en Pleno y por Comisiones", dedica sus dos apartados subsiguientes a contemplar las líneas maestras a las que se ha de ajustar la delegación legislativa de las Cámaras a sus respectivas Comisiones. De acuerdo con el Art. $75.2^{\circ}$ :

«Las Cámaras podrán delegar en las Comisiones Legislativas Permanentes la aprobación de proyectos o proposiciones de ley. El Pleno podrá, no obstante, recabar en cualquier momento el debate y votación de cualquier proyecto o proposición de ley que haya sido objeto de esa delegación".

13 Entre otros muchos, Angelo Antonio Cervati: "La formazione delle leggi", op. cit., p. 146. 
En claro reflejo, en este punto casi mimético, de la Constitución Italiana, el Art. $75.3^{\circ}$ completa el diseño constitucional de este instituto refiriéndose a la reserva de ley de Pleno en los siguientes términos:

"Quedan exceptuados de lo dispuesto en el apartado anterior la reforma constitucional, las cuestiones internacionales, las leyes orgánicas y de base, y los presupuestos Generales del Estado".

La norma en cuestión es inequívocamente tributaria del Art. $72^{\circ}$ de la Carta constitucional italiana, si bien no sólo de ella, pues también parece clara la predeterminación de la fórmula constitucional por la propia praxis parlamentaria generada por la normación reglamentaria del procedimiento legislativo preexistente que, como expondremos más adelante, remonta su origen a la Ley de Cortes de 1942, lo que entraña que también desde una perspectiva histórica pueda establecerse un cierto paralelismo en la regulación de esta peculiar modalidad del procedimiento legislativo entre Italia y España.

II. Singular es, como señala Paladin ${ }^{14}$, el origen histórico de la institución en Italia, pues, como resulta opinión unánimemente compartida por la doctrina, dicho instituto encuentra su germen en la Ley de 19 de enero de 1939, núm. 129, de "Istituzione della Camera dei Fasci e delle Corporazioni $\rangle^{15}$, cuyos artículos $15^{\circ}$ y $16^{\circ}$ normaban en términos semejantes a los ulteriormente dados al instituto en la Constitución de 1947 , el procedimiento legislativo descentralizado ${ }^{16}$.

14 Livio Paladin: “Diritto Costituzionale», CEDAM, Padova, 1991, p. 340.

15 Puede verse el texto de esta ley en Francesco Teresi: "Codice Costituzionale», Zanichelli, Bologna, 1998, pp. 11-12.

$16 \mathrm{El}$ artículo $15^{\circ}$ de la Ley núm. 129, de 1939, atribuía a los Plenos (Assemblee plenarie) de la Cámara de los Fascios y de las Corporaciones y del Senado del Reino, el conocimiento de los proyectos de ley de carácter constitucional, (tal y como ya había establecido el Art. $12^{\circ}$ de la Ley de 9 de diciembre de 1928, núm. 2693, de "Ordinamento e attribuzioni del Gran Consiglio del Fascismo»), las delegaciones legislativas de carácter general, los proyectos de presupuestos y de rendición de cuentas del Estado y de las Haciendas autónomas del Estado y de los entes administrativos de cualquier naturaleza de importancia nacional, subvencionados directa o indirectamente por el Presupuesto del Estado. A su vez, el Art. $16^{\circ}$ atribuía el examen de todos aquellos proyectos de ley no incluidos en el Art. $15^{\circ}$ con carácter exclusivo, a las Comisiones Legislativas de ambas Cámaras. 
La Constitución de 1947 iba, ciertamente, a readaptar el procedimiento acuñado por el régimen fascista a las pautas y principios del régimen democrático. Y a tal efecto se introducía una diferencia que, en principio, parecía fundamental: mientras de acuerdo con la Ley de 1939 las Cámaras en Pleno tenían una competencia estrictamente tasada que parecía convertir en excepcional su intervención en el procedimiento legislativo, correspondiendo a las Comisiones Legislativas una amplísima competencia residual que las convertía en los órganos competentes para conocer y aprobar la inmensa mayoría de los proyectos legislativos, la Carta de 1947 alteraba esa correlación al atribuir a los Plenos de las Cámaras la competencia general, habilitando a las propias Cámaras para determinar, a través de sus respectivos Reglamentos, «los casos y la forma» en los que las Comisiones respectivas podían sustituir a los Plenos en el conocimiento y aprobación de un proyecto de ley. Dicho de otro modo, y según Mazziotti ${ }^{17}$, la sustitución de los Plenos por las Comisiones dependía de la voluntad de los primeros, plasmada en los respectivos Reglamentos. Y esa voluntad de la Cámara sólo podía justificarse en cuanto existía una expresa norma constitucional habilitante, pues, como indica Paladin ${ }^{18}$, los Reglamentos parlamentarios no estarían habilitados para prever y disciplinar un procedimiento de tal naturaleza de no existir la previa habilitación constitucional.

Por todo lo expuesto, Mortati ha podido subrayar la notable diferencia existente entre el régimen de la Ley de 1939 y el de la Carta de 1947 en el punto que nos ocupa, significando ${ }^{19}$ que mientras en la Ley de 1939 las Comisiones tenían una competencia propia (no enumerada expresamente, recordémoslo, sino contemplada de modo residual), que quizá podría haber sido restablecida en alguna medida por los Reglamentos de las Cámaras, al amparo del Art. $72^{\circ}$ de la Constitución, al no haberse decantado por esa fórmula y optar por atribuir al Presidente de la Cámara, salvo oposición de la misma, la iniciativa para deferir en cada ocasión a la Comisión el conocimiento en sede deliberante del proyecto legislativo, las Comisiones han pasado a disponer tan sólo de una com-

17 Manlio Mazziotti di Celso: "Parlamento. Funcioni" (Diritto Costituzionale), en "Enciclopedia del Diritto", tomo XXXI, Giuffrè, Milán, 1981, p. 757 y ss.; en concreto, p. 793 .

18 Livio Paladin: "Diritto Costituzionale», op. cit., p. 342.

19 Costantino Mortati: "Istituzioni di Diritto Pubblico", tomo $11,9^{\circ}$ ed., CEDAM, Padova, 1976 , p. 744 . 
petencia eventual y sustitutoria que deviene actual previa investidura del órgano competente en el procedimiento normal u ordinario.

Por lo demás, la propia estructura del Art. $72^{\circ}$ es ilustrativa de la excepcionalidad, por lo menos en la dicción del texto constitucional, del procedimiento descentralizado. No debe considerarse desprovisto de significado a este respecto que en su párrafo primero el Art. $72^{\circ}$ contemple como procedimiento legislativo normal u ordinario el llamado "procedimento di assemblea" en el que la Comisión tiene una función preparatoria de la ulterior intervención del Pleno, que habrá de aprobar artículo por artículo y en una votación final el proyecto legislativo, conociéndose en estos casos la actividad de la Comisión como "in sede referente». Y en los dos párrafos sucesivos se contemplan dos procedimientos especiales o extraordinarios: el procedimiento abreviado y el procedimiento descentralizado, del que venimos ocupándonos.

No puede, sin embargo, dejar de hacerse una precisión respecto al contraste que se ha venido estableciendo entre la excepcionalidad de la intervención en el procedimiento legislativo por parte de los Plenos de las Cámaras contemplada en la Ley de 1939 y la generalidad o normalidad de esa misma intervención prevista por la Constitución de 1947. En un plano teórico o abstracto, sin lugar a dudas, tal afirmación o contraste es indiscutible, pero en el plano de la realidad de los hechos el juicio debe modificarse o, por lo menos, matizarse sustancialmente. Como afirme Elia ${ }^{20}$, causa una cierta sensación calificar como normal, el "procedimento di assemblea" desde el momento en que se advierte que el de comisión se ha venido utilizando con amplísima ventaja, alrededor de tres veces frente a una ${ }^{21}$. Esta proporción, en torno al 75 por 100 en

20 Leopoldo Elia: "Le commissioni parlamentari italiane nel procedimento legislativo", en Archivio Giuridico "Filippo Serafini", vol. XXIX, fasc. 1-2, Socictà Tipografica Modenese, Módena, 1961, p. 42 y ss.; en concreto, p. 98.

$21 \mathrm{El}$ propio Elia (Ibidem, p. 98, nota 129) nos ofrece datos empíricos de las dos primeras legislaturas del Parlamento italiano. En la primera, sobre un total de 2,427 proyectos de ley aprobados por la Cámara de Diputados, 587 lo fueron por el Pleno y 1,840 en Comisión. En el Senado, de un total de 2,417 proyectos, 628 fueron aprobados por el Pleno y 1,789 en Comisión. En la segunda legislatura, cstos rasgos se acentúan. Y así, en la Cámara de Diputados, de un total de 2,004 proyectos lcgislativos aprobados, 496 lo fueron de acuerdo con el "procedimento di assemblea" frente a 1,508 que lo fueron por el procedimiento descentralizado. Y en el Senado, sobre 1,998 proyectos aprobados, 475 lo fueron según el primer procedimiento y 1,523 de conformidad con el segundo. 
favor del procedimiento descentralizado, como revelan los datos ofrecidos por Martines ${ }^{22}$ se mantendría, incluso en un leve pero constante ascenso, hasta la sexta legislatura, iniciándose en la séptima una inversión de la tendencia que, por ejemplo, ha situado ese porcentaje en la décima legislatura en torno al 54 por 100 . Todo ello conduce a una conclusión evidente: se ha producido un verdadero vuelco en la relación existente entre el procedimiento supuestamente normal, y el formalmente conformado como excepcional. La excepción se ha convertido, pues, en la regla ${ }^{23}$ llegándose, de facto, a una situación análoga a la dimanante de la Ley de 1939.

III. En la Asamblea constituyente italiana se suscitó la problemática de la adopción de una fórmula que pudiera dar respuesta a la exigencia, apreciada por todos los sectores políticos y por parte de la opinión pública, de una legislación rápida y acorde con las nuevas tareas del Estado social de derecho. La adecuación a este nuevo reto del procedimiento legislativo, como recuerda Mohrhoff ${ }^{24}$, fue planteada por vez primera por Mortati en la sesión de la Subcomisión para la Organización del Estado celebrada el 26 de octubre de 1946. Mortati, a la sazón ponente, propuso un sistema de descentralización de la competencia legislativa de las Cámaras caracterizado por la posibilidad de que el Pleno de la Cámara pudiese delegar a las Comisiones el examen del texto de aquellos proyectos legislativos de carácter técnico, en el bien entendido de que el dictamen emirido por la Comisión había de pasar a votación del Pleno sin debate previo alguno, con las meras declaraciones de voto.

El debate plenario en la Asamblea Constituyente osciló entre dos posiciones extremas: la absoluta e inderogable competencia legislativa de las Cámaras en sesión plenaria y la delegación a las Comisiones del examen y aprobación de todos los proyectos de ley que no tuvieran gran

22 Temístocle Martines: “Diritto Costituzionale», 8a. ed., Giuffrè, Milán, 1994. pp. 338-339.

23 Análoga es la conclusión a la que llegó Georges Langrod (en "Quelques aspects de la procédure parlementaire en France, en Italie et en Allemagne Fédéralen, en Revue Internationale de Droit Comparé, París, 1953, núm. 3, julio-setiembre 1953, p. 497 y ss.; en particular, p. 523) si bien quizá demasiado tempranamente.

24 Federico Mohrhoff: "Commissione Parlamentare", en "Novissimo Digesto Italiano" (diretto da Antonio Azara e Ernesto Eula), tomo III, 3a. ed., UTET, Torino, 1967, p. 647 y ss.; en concreto, p. 650. 
importancia política. Una propuesta del diputado Constituyente Vanoni iba a ser decisiva en la redacción final del Art. $72^{\circ}$.

En síntesis, se trataba de deferir a las Comisiones los proyectos relativos a materias estrictamente técnicas y a los Plenos los referentes a materia de notable relevancia política o que implicaran el planteamiento de aspectos principales. Como de nuevo señala Mohrhoff ${ }^{5}$ era una tesis mucho más avanzada que la sostenida por el ponente Mortati quien no la acogió, preocupado por las consecuencias de una excesiva especialización y burocratización de la actividad legislativa. La propuesta final de Ruini, presidente de la Comisión de los setenta y cinco, en el sentido de que pudiese ser deferido a las Comisiones no solo el examen y formulación de los textos legislativos, sino también su aprobación definitiva, resultaría decisiva para la adopción final por el constituyente de esta innovadora fórmula procedimental que constituyó verdaderamente un "quid novi» en la historia de los modernos ordenamientos constitucionales.

IV. La comparación entre la fórmula acuñada por el Art. $75^{\circ}$ de la Constitución de 1978 y la más de seis lustros antes institucionalizada en Italia no deja resquicio alguno a la duda respecto al influjo ejercido por el constituyente transalpino sobre el español ${ }^{26}$. Sin embargo, no es éste el único antecedente que encontramos en la génesis de este instituto procedimental parlamentario, sino que, también al igual que en Italia, es preciso en esta búsqueda de antecedentes remontarse al régimen autoritario anterior, apreciación coincidente entre la doctrina ${ }^{27}$. Desde lue-

25 Ibidem, pp. 650-651.

26 La doctrina es unánime el respecto. Y así, por poner algún ejemplo, Recoder señala que aunque pueda tener otras inspiraciones, la influencia más inmediata deriva de la Constitución italiana. Emilio Recoder de Casso: "Comentario al Art. $75^{\circ}$ de la Constitución", en Fernando Garrido Falla (dir.), "Comentario a la Constitución", 2a. ed., Civitas, Madrid, 1985, p. 1161 y ss., en concreto, p. 1162. En el mismo sentido, Luis Villacorta Mancebo: “Hacia el equilibrio de poderes" (Comisiones Legislativas y robustecimiento de las Cortes), Universidad de Valladolid-Caja de Ahorros y M.P. de Salamanca, Valladolid, 1989, en particular, pp. 363-365.

27 Así, también sin ánimo exhaustivo, entre otros, Ma. Asunción García Martínez: "El procedimiento legislativo», Congreso de los Diputados, Madrid, 1987, p. 294. En igual sentido, Agustín Ruiz, Robledo: “La delegación legislativa en las Comisiones», en Juan Carlos da Silva Ochoa (Coord.), «Las Comisiones Parlamentarias», Parlamento Vasco, Vitoria, 1994, p. 457 y ss.; en concreto, pp. 464-465. 
go, no cabe duda alguna acerca del rechazo radical de los constituyentes hacia las Leyes Fundamentales del franquismo; más aún, buen número de preceptos constitucionales encuentra su razón de ser en una relación dialéctica con el ordenamiento del inmediato pasado autocrático. Sin embargo, en el caso que nos ocupa el influjo de la normativa anterior no sólo se iba a diluir por la incidencia, más fuerte sin duda, del modelo italiano, sino que se iba asimismo a canalizar a través de otras vías normativas distintas de las Leyes Fundamentales (aunque fueran en último término desarrollo de ellas), como sería el caso de los Reglamentos de las Cortes, particularmente el de 1971, en el que en algunos aspectos, como el procedimiento que venimos analizando, encontrarían su inspiración los Reglamentos provisionales del Congreso de los Diputados y del Senado, de 17 y 18 de octubre de 1977, respectivamente, normas estas últimas que no podían por menos que incidir en la adopción por los constituyentes del procedimiento legislativo descentralizado. Nos detendremos más en ello.

El Art. $10^{\circ}$ de la Ley constitutiva de las Cortes de 17 de julio de 1942 reservaba al Pleno las leyes que tuvieran por objeto alguna de las materias en él enumeradas. A su vez, el Art. $12^{\circ}$ consideraba de la competencia de las Comisiones de las Cortes todas las disposiciones que no estuvieran comprendidas en el Art. $10^{\circ}$ y debieran revestir forma de ley. La analogía con la Ley italiana de 1939 era bien patente.

El Reglamento de las Cortes Españolas de 26 de diciembre de 1957 primero propiamente dicho, omisión hecha del Reglamento provisional de 5 de enero de 1943, contemplará la tramitación de los proyectos de ley en un Título específico (el Título VI) subsiguiente al dedicado a las Comisiones (Titulo V) y anterior al relativo al Pleno de las Cortes (Título IX) cuyas reuniones preceptivas se fijan en dos veces por lo menos al año, "así como para la aprobación de los actos o leyes especificados en el Art. $10^{\circ}$ de la Ley de Cortes (Art. 61.2 del Reglamento). Es notorio y patente el significado radicalmente distinto de este antecedente, pues, como bien se ha dicho ${ }^{28}$, no son razones técnicas las que inclinan a un régimen no democrático a refugiar la legislación en las Comisiones, sino razones políticas: reducir a la mínima expresión los debates con luz y taquígrafos. Las Comisiones son más manejables que las reuniones plenarias. 
Tras la reforma operada por la Ley de 22 de julio de 1967 sobre el Reglamento de 1957 se llega al Reglamento de 15 de noviembre de 1971 , primera norma de este tipo que se refiere específicamente al procedimiento legislativo, diferenciando los procedimientos legislativos ordinarios (Título IX) de los especiales (Título X) y dentro de estos últimos, el procedimiento de tramitación de los proyectos de ley que sean competencia de las Comisiones (Capítulo primero, arts. $89^{\circ}$ a $\left.91^{\circ}\right)^{29}$. Será la primera vez en que la tramitación de los proyectos de competencia de las Comisiones sea desarrollado con arreglo a un procedimiento "ad hoc», como recuerda Fraile ${ }^{30}$, hasta entonces no hay sino un procedimiento único que se bifurca en su fase final, yendo unos proyectos para aprobación del Pleno y otros para su simple dación de cuentas.

A la hora de diferenciar los proyectos que no eran de la competencia del Pleno, el propio autor anterior llega a la conclusión ${ }^{3 t}$ de que prácticamente coincidía la distinción con la de leyes materiales y formales, bien que éste sólo fuera un criterio aproximativo en tanto que la determinación del procedimiento a seguir requería un acto de calificación individual del Presidente para cada proyecto que se explicitaba en el Decreto de publicación del proyecto de ley. ${ }^{32}$

Tras las elecciones del 15 de junio de 1977, las nuevas cámaras democráticamente elegidas iban a aprobar unos reglamentos provisionales que pervivirian hasta la entrada en vigor de los hoy vigentes, de 1982 el del Congreso y de 1994 el Texto Refundido del Reglamento del Senado. Sobre ambos Reglamentos provisionales iban a influir algunas de las

29 Como indicara Ruiz Robledo, doctrinalmente hubiera sido más congruente calificar el procedimiento en comisión como el ordinario y al que se celebraba en el Pleno como especial porque éste era el que tenía un ámbito de actuación tasado. Agustín Ruiz Robledo: "Sobre los tipos de procedimientos legislativos», en el colectivo, «El procedimiento legislativo" (V Jornadas de Derecho Parlamentario), Congreso de los Diputados, Madrid, 1997, p. 653 y ss.; en concreto, p. 656.

30 Manuel Ma. Fraile Clivillés: "Comentario al Reglamento de las Cortes” Instituto de Estudios Políticos, Madrid, 1973, p. 856.

31 Ibidem, pp. 855-856.

32 Tomás-Ramón Fernández constata que en el régimen franquista se hizo un uso muy moderado de las Leyes de Comisión, limitándolas de hecho a la ratificación de ciertos Tratados, aprobación de Leyes de gasto público y Leyes de carácter organizativo de pequeña trascendencia. Eduardo García de Enterría y Tomás-Ramón Fernández: "Curso de Derecho Administrativo", tomo I, 4a . ed. reimpr., Civitas, Madrid 1986, p. 158. 
normas reglamentarias establecidas en el Reglamento de 1971, quizá por la notable calidad técnica de esta última norma. Además, en lo que atañe al instituto que nos ocupa, como bien se advierte ${ }^{33}$, sin duda pesó la inercia de la institución. Ello se tradujo en que el Reglamento provisional del Congreso, dentro del Título referente al procedimiento legislativo, y en el Capítulo dedicado al procedimiento legislativo ordinario acogiese una Sección relativa a la competencia legislativa plena de las Comisiones Permanentes. A tenor del artículo único de esa Sección (Art. $\left.102^{\circ}\right)$.

1. «En los proyectos y proposiciones que no traten de materias de especial importancia de orden general, la Mesa del Congreso puede decidir que la Comisión encargada de dictaminar el texto en cuestión lo haga en plenitud de poder legislativo, sin exigirse su aprobación final, en el Pleno del Congreso. El acuerdo será publicado en el "Boletín Oficial de las Cortes"”.

2. "No obstante, si, en el plazo de tres días a partir de la publicación del anterior acuerdo, dos Grupos parlamentarios o cincuenta diputados expresaran un parecer contrario a aquélla, el asunto será resuelto por el Pleno de la Cámara».

De la forma en cuestión ha de destacarse, en primer término, el hecho de la indeterminación con que se contemplaban los proyectos que podían ser aprobados definitivamente por una Comisión. El precepto se refería a aquellos proyectos y proposiciones «que no traten de materias de especial importancia de orden general». La fórmula era excesivamente vaga y potenciaba hasta el extremo la facultad atribuida a la Mesa del Congreso de decidir que la Comisión encargada de dictaminar el texto en cuestión lo hiciera en plenitud de poder legislativo, al disponer la Mesa de una amplísima facultad de calificación. Lógicamente, antes de adoptar tal decisión, la Mesa había de valorar la importancia de orden general del proyecto o proposición y, a la vista de la misma, adoptar la pertinente decisión. Bien es verdad que tan exagerada capacidad decisoria por parte de la Mesa se veía contrapesada por la intervención del Pleno que, a instancia de dos Grupos parlamentarios o cincuenta diputados, que se manifestaran contrariamente, había de zanjar la cues-

33 Juan Luis Paniagua Soto: «El Sistema de Comisiones [...]», op. cit., p. 131. 
tión, resolviendo en uno u otro sentido la controversia en torno a la sede parlamentaria, Comisión o Pleno, que había de aprobar finalmente el texto del proyecto o proposición.

El Reglamento provisional del Senado establecía un cierto automatismo para la adopción del procedimiento descentralizado al disponer su artículo $86.2^{\circ}$ que los proyectos y proposiciones de ley que hubieran sido aprobados por la Comisión competente del Congreso con plenitud de poder legislativo, "pasarán a la Comisión correspondiente del Senado, que tendrá el mismo poder, sin exigirse aprobación final en Pleno del Senado". Se optaba así en favor de un mecanismo automático por el que el procedimiento legislativo del Senado se vinculaba, sin posibilidad de cambio alguno, al procedimiento descentralizado seguido en el Congreso. Este desencadenaba aquél. Y ello, parece obvio, no se acomodaba en absoluto al principio de autonomía de la Cámara alta.

Estos antecedentes no podían por menos que influir en la opción final del constituyente de consagrar en el Texto fundamental este peculiar procedimiento legislativo. Pensemos que además del influjo del modelo italiano, las propias Cámaras constituyentes habían institucionalizado ya en sus propias normas reglamentarias ese instituto que, aun encontrando su más remoto origen en la Ley de Cortes de 1942, se había encauzado por intermedio de los Reglamentos de las Cortes hasta llegar por este cauce a los Reglamentos provisionales de 1977.

V. El «iter» constituyente no aporta muchos datos en torno a la constitucionalización de la delegación legislativa de las Cámaras en las Comisiones Permanentes.

En la sesión celebrada por la Ponencia constitucional el 4 de octubre de 1977 se analizaba la posibilidad de la existencia de un procedimiento legislativo abreviado, acordándose su incorporación al texto así como la reserva de ciertas materias para su conocimiento por el Pleno, quedando, no obstante, sin redactar el artículo correspondiente. ${ }^{34}$

En el Anteproyecto constitucional, publicado el 5 de enero de 1978 , las previsiones del actual artículo $75.2^{\circ}$ y $3^{\circ}$ ya aparecían redactadas de un modo sustancialmente análogo en el entonces Art. $66.2^{\circ}$ y $3^{\circ}$. Omisión hecha de una enmienda de estilo (la núm. 691) del Sr. López Rodó, 
solo se presentó una enmienda por parte del Grupo Parlamentario Mixto (la núm. 512) que, lisa y llanamente, optaba por suprimir la figura de la delegación legislativa en Comisión. La Ponencia rechazó en su Informe de modo un tanto lacónico la enmienda del Grupo Mixto por apartarse sustancialmente del sentir común. ${ }^{35}$

Tanto la Comisión de Asuntos Constitucionales del Congreso como el Pleno de la Cámara mantuvieron la redacción que ya sólo se vería modificada en el Senado a raíz de una enmienda (la núm. 334) presentada por el senador Sr. Sánchez Agesta al texto del Art. 69.2 $2^{\circ}$ del Proyecto de Constitución aprobado por el Congreso. ${ }^{36}$ Como en su fundamentación se afirmaba, la enmienda era, en parte, una corrección de estilo "para indicar más precisamente lo que se quiere decir», pero también pretendía «afirmar directamente la posibilidad de revocar la delegación concedida a las Comisiones." En definitiva, como el propio senador Sr. Sánchez Agesta indicaría en la Comisión de Constitución del Senado, ${ }^{37}$ la nueva redacción, aún no cambiando nada en lo esencial, lo precisaba, en cuanto que lo que venía a posibilitar la norma en cuestión era revocar una delegación. La Comisión aprobaría tal enmienda, quedando de esta forma el precepto con la redacción que a la postre habría de ser la definitiva.

\section{Naturaleza jurídica de la institución}

I. Una cuestión relevante y especialmente controvertida en Italia ha sido la relativa a la calificación jurídica del título competencial de las Comisiones al aprobar los proyectos de ley.

La tesis de que la traslación a las Comisiones de la facultad de aprobar los proyectos legislativos constituía una auténtica delegación ya fue sostenida durante los trabajos preparatorios de la Asamblea Constituyente italiana. Como recuerda la doctrina, ${ }^{38}$ en ese momento encontró amplio seguimiento en la Constituyente la opinión de que se trataba de

35 Fernando Sáinz Moreno: "Constitución Española. Trabajos Parlamentarios". tomo I; Cortes Generales, 2a. ed., Madrid, 1989, p. 546.

36 Ibidem, tomo III, pp. 2808-2809.

37 Ibidem, tomo IV, pp. 3738-3739.

38 Guiseppe D'Eufemia: «Le Commissioni Parlamentari [...]”, op. cit., p. 44. 
una suerte de otorgamiento de actividad legislativa a las Comisiones por parte de las Cámaras y que, por ello mismo, se estaba en presencia de una delegación a órganos diversos del Parlamento a los que el propio texto constitucional otorgaba competencia legislativa.

Entre la doctrina ulterior ha sido Mortati quien con más ahínco ha insistido en la figura de la delegación para calificar jurídicamente el título competencial de las Comisiones. ${ }^{39}$ A juicio del citado autor, los Reglamentos, de las Cámaras habrían podido establecer alguna competencia propia de las Comisiones, como aconteció con la Ley de 19 de enero de 1939, núm. 129, aunque no lo han hecho, determinando por el contrario que la traslación competencial tenga lugar en cada ocasión por iniciativa del Presidente salvo oposición de la Cámara. Por lo mismo, Mortati entiende que las Comisiones, como ya indicamos en un momento precedente, poscen tan sólo una competencia eventual y subrogatoria que se convierte en efectiva o real previa investidura del órgano competente en vía normal; por todo ello, Mortati entiende adecuado reconducir el caso en cuestión a la figura. jurídica de la delegación.

Esta tesis no ha sido, sin embargo, aceptada pacíficamente por la doctrina. Todo lo contrario. Y así, por un lado, Balladore-Pallieri ${ }^{40}$ rechaza que exista delegación al considerar que las Comisiones no son, por lo menos hacia el exterior, órganos distintos de los Plenos de las Cámaras a las que pertenecen, y que la deliberación a través de la Comisión no es más que una de las modalidades a cuyo través se admite que la Cámara puede deliberar, circunstancia que conduce a entender que la deliberación es siempre de la Cámara y, en consecuencia, no cabe delegación alguna. ${ }^{41}$ Este es precisamente el argumento al que recurre Pierandrei ${ }^{42}$ para rebatir la crítica de que la traslación del ejercicio de la

39 Costantino Mortati: "Istituzioni di Diritto Pubblico", tomo II, 9a. ed., CEDAM, Padova, 1976, pp. 744-746.

40 G. Balladore-Palliri: «Diritto Costituzionale», 5. ed., Giuffré, Milán, 1957, p. 221.

41 Análoga es la posición de Sandulli, para quien las Comisiones son órganos internos de la Cámara a la que pertenecen, por lo que la determinación del Pleno de deferir un proyecto a una Comisión no puede ser considerada mas que como la elección de una mera opción procedimental de igual modo, por ejemplo, que la elección en favor de un determinado sistema de votación. Aldo M. Sandulli: "Legge" (Diritto costituzionale), en "Novissimo Digesto Italiano", tomo IX (diretto da Antonio Azara e Ernesto Eula), 3a. ed., UTE, Torino, 1965, p. 630 y ss.; en concreto, p. 640.

42 Franco Pierandrei: "Le Commissione Legislative del Parlamento Italiano", op. cit. pp. $84-85$. 
actividad legislativa a las Comisiones es contraria al principio constitucional de que el poder legislativo pertenece a las Cámaras parlamentarias que presupone que la competencia legislativa de estas no puede ser delegada a otros órganos. Pierandrei cree que esa objeción está viciada en su origen por cuanto que el principio "delegatus delegare non potest» no tiene valor alguno en este caso. Y ello tanto porque la doctrina según la cual el poder legislativo que ejerce el Parlamento estaría delegado a este último por el pueblo, tiene una significación exclusivamente política, cuanto porque las Comisiones no son órgamos diferentes de las Cámaras, sino órganos de las propias Cámaras, por lo que en la medida en que las Comisiones legislan, sus manifestaciones de voluntad pertenecen a las propias Cámaras de las que forman parte. Abundando en esta línea, D'Eufemia ${ }^{43}$ considera que entre la Asamblea en Pleno y las Comisiones en sede deliberante la competencia se reparte de modo análogo a la relación que media entre un órgano primario y un órgano secundario. Las Comisiones en sede deliberante son el órgano secundario de la correspondiente Asamblea en Pleno y el acto presidencial que traslada la aprobación del proyecto legislativo a la Comisión constituye la condición que posibilita a la Comisión el ejercicio de la función legislativa en nombre y por cuenta de la Asamblea en Pleno, que a su vez dispone de la facultad de avocación en los términos constitucionalmente establecidos. No se trata, pues, siempre según D’Eufemia, de una delegación, sino de una relación orgánica en la que la Comisión es un órgano de otro órgano.

En contra asimismo de la tesis minoritaria de la delegación ${ }^{44}$, se ha considerado también que no sólo no es necesaria una deliberación del Pleno para deferir la aprobación del proyecto a la Comisión, siendo el Presidente de la Cámara el efectivo delegante, sino que más allá de esa objeción, ha sido el propio constituyente quien ha repartido de modo permanente la potestad legislativa de las Cámaras entre dos órganos internos de las mismas Cámaras: el Pleno y las Comisiones legislativas. ${ }^{45}$ Esta reflexión, a su vez debe ser, según Elia, ${ }^{46}$ el punto de partida para resolver la problemática que nos ocupa.

43 Giuseppe D’Eufemia: "Le Commissioni Parlamentari [...]", op. cit., pp. 45-46.

44 Junto a Mortati se ha inclinado también en favor de esta tesis Paolo Biscaretti, en su "Derecho Constitucional", Tecnos, Madrid, 1973, p. 394.

45 Pietro Virga: “Diritto Costituzionale», 6ª ed., Giuffrè, Milán, 1967, pp. 337-338.

46 Leopoldo Elia: "Commissione Parlamentari", en "Enciclopedia del Diritto", Vol. VII, Giuffrè, Milán, 1960, p. 895 y ss.; en concreto, pp. 901-902. 
Elia parte de la consideración de que la relevancia autónoma de las Comisiones respecto de las Cámaras en Pleno no descansa en una mera diferenciación estructural, sino sobre un diverso tratamiento jurídico. El punto de apoyo que permite atribuir relevancia externa a la competencia de las Comisiones y a la de los Plenos ha de verse en la limitación del último párrafo del Art. $72^{\circ}$, esto es, en la reserva de ley de Pleno ( (riserva di legge d'Assemblea»). Si tal reserva faltase, la diferenciación entre el procedimiento normal u ordinario y el procedimiento en comisión deliberante habría tenido un carácter puramente interno, eliminando "in radice" la necesidad hoy existente de distinguir entre las "leyes de Pleno» (legge di assemblea) y las «leyes de Comisión» (legge di commissione). Parece claro que no se trata de un problema formal, pues la reserva del último párrafo del Art. $72^{\circ}$ confiere relieve práctico a la distinción entre el procedimiento ordinario y el descentralizado al objeto de garantizar de algún modo y para ciertas categorías de proyectos legislativos, un pronunciamiento cualificado de un órgano, pues es obvio que la deliberación en sede plenaria viene cualificada por un conjunto de garantías que van desde el mayor número de miembros hasta la más amplia publicidad procedimental, pasando por la muy relevante presencia de las formaciones políticas conformadas tal y como emergieron de la elección del cuerpo electoral.

A los elementos de diferenciación referidos se ha de añadir la posibilidad, en manos de la "Corte Costituzionale" de hacer respetar el reparto competencial fijado por el último párrafo del Art. $72^{\circ}$, posibilidad expresamente contemplada por la propia "Corte» en su Sentencia de 3-9 de marzo de 1959, y núm. 9, ${ }^{47}$ que pese a levantar una fuerte polémica doctrina ${ }^{48}$ y pese asimismo a lo insatisfactorio de algunos de sus planteamientos. ${ }^{49}$ Supuso una inequívoca toma de postura por parte de la "Corte» en favor de su competencia para controlar la observancia de las

47 Puede verse la sentencia en "Guirisprudenza Costituzionale», 1959, p. 237 y ss.

48 Sobre la polémica, y dentro de la doctrina española, cfr. Paloma Biglino Campos: "Los vicios en el procedimiento legislativo", Centro de Estudios Constitucionales, Madrid, 1991. p. 24 y ss. Asimismo, Ignacio Torres Muro: «El control jurisdiccional de los actos parlamentarios. La experiencia italiana» (1), en Revista Española de Derecho Constitucional, núm. 17, mayo-agosto 1986, p. 189 y ss.; en especial, pp. 198-215.

49 Cfr. al respecto Paolo Barile: "Il crollo di un antico feticcio (gli interna corporis') in una storica (ma insoddisfacente) sentenza", en "Gitursprudenza Costituzionale», 1959, p. 240 y ss. 
normas constitucionales sobre el procedimiento de formación de las leyes. ${ }^{50}$ Como reconoce la Corte, "la posizione costituzionale di indipendenza delle Camere non implica [...] l'assoluta insindacabilità, da parte di qualsiasi altro organo dello Stato, del procedimento con cui. gli atti delle Camere vengono deliberati, ed in particolare l'insindacabilità da parte della Corte costituzionale del procedimento di formazione di una legge». ${ }^{51}$

Cuantos argumentos se han expuesto parecen suficientes, a juicio de Elia, ${ }^{52}$ para rechazar la opinión dominante que desconoce la existencia dentro del órgano complejo que es una Cámara de varios órganos diferentes por su competencia y por su dignidad: el Pleno y las Comisiones.

II. Si en Italia, como ha podido verse, la polémica doctrinal en torno a la naturaleza jurídica del acto de traslación ("atto di deferimento») o asignación del proyecto legislativo a la Comisión ha sido intensa, no puede decirse otro tanto de España donde el tema ha suscitado mucha menor inquietud entre la doctrina. La diferente dicción del Art. $75.2^{\circ}$ CE respecto a la redacción del párrafo tercero del Art. $72^{\circ} \mathrm{CI}$ tiene mucho que ver con ello.

El Art $75.2^{\circ} \mathrm{CE}$, a diferencia del texto italiano, omite toda alusión al Reglamento, soslayando de esta forma las críticas que en Italia suscitó la remisión a la norma reglamentaria, que era la que debía determinar «los casos y la forma» ( in quali casi e forme») en que sería procedente trasladar el examen y aprobación de los proyectos legislativos a las Comisiones; dicho de otro modo, el reglamento parlamentario de cada Cámara, respetando las reservas de Pleno del párrafo cuatro del Art. $72^{\circ}$, debía proceder al reparto de competencia entre el Pleno y las Comisiones, reparto que finalmente se reveló como imposible de llevar a cabo. Las críticas anteriormente aludidas tuvieron su origen, como recuerda la doctrina, ${ }^{53}$ en el temor de que la atribución a los Reglamentos de la determinación de los "casos" en que las Comisiones habían de asumir un poder legislativo pleno, supusiera una rígida determinación de las materias a asignar a las Comisiones, privando automáticamente a los Plenos de las Cámaras del conocimiento de ciertas disposiciones legisla-

50 Sentencia de la Corte núm. 9 de 1959, Considerato in diritto 2.

51 Ibidem, Considerato in diritto 5.

52 Leopoldo Elia: “Commissione Parlamenteri", op. cit. p. 902.

53 Franco Pierandrei: "Les Commissions Législatives du Parlement Italien", op. cit., p. 572 . 
tivas, que, teniendo a primera vista una modesta importancia, presentara en realidad un notable interés político.

No será, pues, el Reglamento el que atribuya la aprobación de las leyes de las Comisiones Legislativas Permanentes, sino que será la propia Constitución la que prevea directamente una posible "delegación" a modo de facultad de las Cámaras, que resultan constitucionalmente habilitadas para llevar a cabo la delegación ("podrán delegar a las Comisiones", dice literalmente el Art. $75.2^{\circ} \mathrm{CE}$ ). Según Recoder, ${ }^{54}$ esto quiere decir que lo que la doctrina italiana ha construido con dificultades, nuestra Constitución lo acoge rotundamente: hay una delegación de la Cámara a las Comisiones, tesis que suscribe la totalidad de la doctrina. ${ }^{55}$

El debate constituyente corrobora esta tesis. Pero a su evidente parquedad en este punto, se puede advertir que en las escasas oportunidades en que el tema se suscitó, siempre se manejó el concepto de "delegación” o, en su caso, el de revocación de la delegación, lo que es revelador de que en todo momento existió cierta convergencia en torno a la calificación jurídica del título competencial de las Comisiones.

El concepto de "delegación», uno de los más complejos del Derecho público, ${ }^{56}$ identifica una técnica que presupone que el órgano delegado no ejerce ninguna competencia propia, sino la competencia de otro órgano; es decir, la delegación transfiere el ejercicio pero no la titularidad de la competencia. ${ }^{57}$ De ahí que al menos en la delegación interorgánica,

54 Emilio Recoder de Casso: “Comentario al artículo 75\%", op. cit., p. 1166.

55 Asunción García Martínez: «El procedimicnto lcgislativo», op. cit. p. 294. Juan Luis Paniagua Soto: "El sistema de comisiones [...]». op. cit., p. 134. Agustín Ruiz Robledo: "La delegación legislativa en las Comisiones", op. cit., pp. 467-468. Luis Villacorta Mancebo: "Hacia el equilibrio de poderes", op. cit., p. 380 . Florentina Navas Castillo: "La función legislativa y de control en Comisión parlamentaria: Comisiones de Investigación y Comisiones Legislativas Permanentes con competencia legislativa plena", Colex, Madrid 2000, p. 99.

56 Alfredo Gallego Anabitarte: «Transferencia y descentralización; delegación y desconcentración; mandato y gestión o encomienda", en Revista de Administración Pública, núm. 122, mayo-agosto 1990, p. 7 y ss.; en concreto, p. 49.

57 Jiménez Campo, aun admitiendo la frecuencia con que se utiliza, incluso reglamentariamente, la noción de "competencia" para aludir a las funciones de las Comisiones, considera que tal noción es escasamente útil, y hasta perturbadora, para definir las relaciones entre Comisión y Cámara. Javier Jiménez Campo: «Sobre el control parlamentario en Comisión", en "Política y Sociedad" (Estudios de homenaje a Francisco Murillo Ferrol), vol. I, CIS-CEC, Madrid, 1987, p. 477 y ss.; en concreto, p. 482. 
como es el caso, aunque no en la intersubjetiva, esto es, la que tiene lugar entre personas jurídicas diferentes, ${ }^{58}$ los actos del delegado en su calidad de tal se entiendan dictados a todos los efectos por el delegante, cuya libre capacidad se manifiesta en una doble dimensión: la falta de capacidad del delegado, en este caso de la Comisión, para desplegar espontáneamente sus facultades, y la habilitación del delegante para revocar «ad nutum» la delegación. Estos rasgos caracterizan, o más bien debieran caracterizar, pues, como más adelante veremos, alguno de ellos no se da en rigor en el Congreso de los Diputados, la delegación legislativa a las Comisiones.

De todo lo expuesto puede derivarse una consecuencia adicional: la asunción por las Comisiones de un poder legislativo pleno no entraña su conversión en órganos independientes, autónomos y externos a las Cámaras. Como bien dice Villacorta, ${ }^{59}$ la delegación de una función por el Pleno en las Comisiones no supone elevar a éstas a la categoría de órgano de naturaleza diferente, sino simplemente incorporar una función diversa a realizar por el mismo órgano.

El Parlamento, como precisara Manzella ${ }^{60}$ en cuanto expresión directa de la voluntad popular, es un órgano único de estructura compleja, y ello, entre otros aspectos, se manifiesta en las articulaciones de cada Cámara como, por ejemplo, en las Comisiones permanentes, articulaciones éstas que se caracterizan por una específica esfera de autonomía constitucionalmente garantizada, reflexión que el propio Manzella considera perfectamente válida para las Comisiones deliberantes en sede legislativa. Insistiendo en la misma idea, Pizzorusso ${ }^{61}$ ha señalado que las articulaciones internas de cada Cámara actúan como representantes del Parlamento en su integridad, lo que, con la mayor evidencia, ocurre en el caso de las leyes aprobadas por las Comisiones.

En todo caso, conviene precisar que aunque la competencia para aprobar proyectos legislativos por parte de las Comisiones no sea propia sino delegada, ello no obsta para que, como de nuevo significa Manzella, ${ }^{62}$

58 Cfr. Al respecto J.J. Lavilla Rubira: "Delegación» (Derecho Administrativo), en "Enciclopedia Juridica Básica», Vol. II, Civitas, Madrid, 1995, p. 1964 y ss.

59 Luis Villacorta Mancebo: "Hacia el equilibrio de poderes», op. cit., p. 381.

60 Andrea Mancella: "Il Parlamento", Il Mulino, Bologna, 1977, p. 65.

61 Alcjandro Pizzorusso: "Lecciones de Derecho Constitucional", CEC, vol. I, Madrid, 1984, p. 267.

62 Andrea Mancella: "Il Parlamento», op. cit., p. 66. 
una vez puesto en marcha este mecanismo, la esfera de autonomía de las Comisiones no pueda ser atacada por otros órganos si no es en la forma expresamente prevista por la propia Constitución.

III. En conexión con la cuestión que acabamos de abordar se ha suscitado el tema de la naturaleza del procedimiento que se ha de seguir por las Comisiones con competencia legislativa plena, y en íntima relación con tal problema se ha planteado incluso una cierta controversia terminológica en torno a la denominación de este procedimiento.

La primera reflexión que se ha de hacer al respecto atañe a la deficiente ubicación del precepto constitucional, pues, como se ha dicho ${ }^{63}$, el Art. $75^{\circ} \mathrm{CE}$ está regulando una variante del procedimiento legislativo en mayor medida que señalando una característica organizativa de las Comisiones. Por lo mismo, creemos que hubiera sido más lógico que se ubicara en el Capítulo segundo del Título III, relativo a la elaboración de las leyes. Los Reglamentos parlamentarios han subsanado esta deficiencia al ubicar las normas de desarrollo del precepto constitucional dentro del procedimiento legislativo: en la sección quinta (de la competencia legislativa plena de las Comisiones) del Capítulo tercero (de las especialidades en el procedimiento legislativo) del Título $\mathrm{V}$ (del procedimiento legislativo), el Reglamento del Congreso, y en la sección segunda (de la delegación de la competencia legislativa en las Comisiones) del Capítulo segundo (de los procedimientos legislativos especiales) del Título IV (del procedimiento legislativo), el Reglamento del Senado.

Como puede apreciarse, este procedimiento se sitúa entre los procedimientos legislativos especiales si bien, en razón al carácter preferente que le concede el Reglamento del Congreso, Santaolalla ${ }^{64}$ ha podido decir que constituye un procedimiento tan común como el propiamente considerado por el Reglamento de la Cámara baja como procedimiento legislativo común.

El procedimiento ha sido en ocasiones calificado de "procedimiento abreviado" ${ }^{65}$ junto con el de urgencia y el de lectura única. Sin embar-

63 Emilio Recoder de Casso: “Comentario al artículo $75^{\circ}$ ", op. cit., p. 1162.

64 Fernando Santolalla López: “Derecho Parlamentario español», Editora Nacional, Madrid, 1984, p. 237.

65 Ruiz Robledo, por ejemplo, se muestra reticente a tildar de "especial» el procedimiento descentralizado, prefiriendo llamarlo «abreviado". Agustín Ruiz Robledo: "La Delegación Legislativa en las Comisiones», op. cit., p. 469. 
go, como señala García-Escudero, ${ }^{66}$ esta equiparación no es adecuada, porque en este procedimiento no se produce sólo un acortamiento de plazos o eliminación de fases, sino una diferencia cualitativa o sustantiva, como es el cambio en el órgano que realiza la aprobación del proyecto. En la misma dirección, Pizzorusso ${ }^{67}$ significa que en el procedimiento descentralizado se da lugar no sólo a una abreviación del procedimiento (por la unificación de las dos fases del procedimiento ordinario que se desarrollan, respectivamente, ante el Pleno y la Comisión), sino también a que el acuerdo final corresponda a un órgano distinto del Pleno de la Cámara, aunque representativo del mismo.

Una última cuestión se ha suscitado respecto del procedimiento legislativo que venimos examinando: la de su propia denominación. Ruiz Robledo $^{68}$, tras mostrar su falta de convencimiento por la denominación de "procedimiento descentralizado", se inclina por llamarlo «desconcentrado», término que, a su juicio, marcaría más claramente la idea de subordinación entre el Pleno y las Comisiones. A su vez, Navas Castillo $^{69}$ tras considerar asimismo poco rigurosa la expresión "procedimiento descentralizado", rechaza de igual forma la denominación de "procedimiento desconcentrado", decantándose por la de "procedimiento legislativo delegado".

Desde luego, si buscamos la definición jurídica de los conceptos de «descentralización»y «desconcentración» podemos llegar con cierta facilidad a la conclusión de que estos términos, no ilustran sobre la calificación jurídica del título competencial de una Comisión al aprobar un proyecto legislativo, que como ya hemos examinado, es la de «delegación". La "descentralización» supone una transferencia competencial intersubjetiva de la titularidad y ejercicio de la competencia, y es claro, como ya se ha dicho, que el Pleno y las Comisiones no parece que pue-

66 Piedad García-Escudero Marquez: "Las especialidades del procedimiento legislativo en el Senado", en el colectivo, "El procedimiento legislativo, 1994", (V Jornada de Derecho Parlamentario), Congreso de los Diputados, Madrid, 1997, p. 481 y ss., en particular pp. 499-500.

67 Alessandro Pizzorusso: "Lecciones de Derecho Constitucional", tomo II, op. cit. pp. 240-241.

68 Agustín Ruiz Robledo: "La delegación legislativa en las Comisiones», op. cit. pp. 466-468.

69 Florentina Navas Castillo: “La función legislativa y de control en Comisión Parlamentaria [...]", op. cit., pp. 105-106. 
dan ser consideradas como personas jurídicas distintas. La «desconcentración" se produce entre órganos de una misma persona jurídica, con lo que se soslaya la objeción anterior, pero, sin embargo, este concepto presupone la transferencia de la titularidad y el ejercicio de la competencia, y como también se ha expuesto, no parece que pueda admitirse que el poder legislativo pleno de las Comisiones entrañe una transferencia de la titularidad de la competencia. Por todo ello, en rigor, ninguno de los dos conceptos calificaría con precisión el título competencial de las Comisiones al aprobar los proyectos de ley, lo que por otro lado es evidente por cuanto, como ya se dijo, la calificación precisa al respecto la encontramos en el concepto de «delegación». En coherencia con ello habría que hablar de procedimiento delegado. Sin embargo, no creemos que la identificación del procedimiento deba venir en función de la calificación jurídica del título competencial de las Comisiones al aprobar el proyecto. Es significativo al respecto que la sección del Reglamento del Congreso que norma este procedimiento lleve por rótulo «De la competencia legislativa plena de las Comisiones», obviando toda referencia a la delegación, aunque no suceda así en el Reglamento del Senado.

En definitiva, no parece que el hecho de que, en el supuesto contemplado, la relación establecida entre el Pleno y las Comisiones deba calificarse como «delegación» deba desencadenar de modo inexcusable que el procedimiento de aprobación de las leyes en Comisión haya de recibir la denominación de "procedimiento delegado". Llamarlo «descentralizado" no significa en modo alguno alterar la naturaleza jurídica de aquella relación. Por ello y por el arraigo doctrinal, de esa expresión, especialmente entre la doctrina italiana, optamos por mantener esa denominación.

\section{La reserva de ley de Pleno}

I. El Art. $75.3^{\circ} \mathrm{CE}$ exceptúa de la delegación de la competencia legislativa a las Comisiones una serie de materias que quedan de tal forma reservadas a su aprobación por el Pleno. Son tales materias las siguientes: la reforma constitucional, las cuestiones internacionales, las leyes orgánicas y de bases y los Presupuestos Generales del Estado.

La norma constitucional española tiene como antecedente más próximo la previsión del último párrafo del Art. $72^{\circ} \mathrm{CI}$ (Constitución Italia- 
na), que reserva el procedimiento normal de examen y aprobación directa por el Pleno para los proyectos de ley en materia constitucional y electoral y para las de delegación legislativa, autorización para ratificar tratados internacionales, aprobación de presupuestos y de cuentas. Se establece así lo que en Italia se conoce como una uriserva di legge di assemblea».

La Ley $\mathrm{N}^{\circ} 129$, de 1939, como expusimos con anterioridad, ya estableció una reserva de esta naturaleza en la que cabe ver el origen remoto de la previsión constitucional que nos ocupa, si bien existe una importante diferencia entre la reserva establecida en la Ley de 1939 y la que determina la Constitución de 1947: en la primera, a tenor del Art. $17^{\circ}$ de la propia Ley, tal reserva podía decaer cuando el Jefe del Gobierno así lo decidiera por razones de urgencia, fórmula perfectamente acorde con un régimen autoritario como el fascista; por el contrario, en la Carta de 1947 esta limitación material, no puede ser evadida; como dice Mazziotti, ${ }^{70}$ constituye un límite absoluto a la competencia legislativa plena de las Comisiones.

Existe una clara coincidencia entre la doctrina italiana y española acerca de la razón de ser de esta reserva. La importancia políticoinstitucional de los proyectos de ley excluidos del conociniento exclusivo por las Comisiones es patente a la vista de las materias por ellos normadas y justifica una previsión constitucional de este tipo. Como sostiene Cervati ${ }^{71}$, refiriéndose a la cláusula constitucional italiana, aunque su reflexión sea perfectamente válida para la norma análoga de la Constitución de 1978, se trata de un conjunto de presupuestos que siendo heterogéneos vienen, sin embargo, caracterizados por un rasgo común: su notable trascendencia en relación con el «indirizzo politico» general o con el mantenimiento del orden constitucional ${ }^{72}$. Ese elemento común, su relevancia político-institucional, debe ser tenido en cuenta a la hora de interpretar las materias mencionadas por el último párrafo del Art. $72^{\circ}$, no tanto con la finalidad de identificar nuevos supuestos de proyectos legislativos cuya aprobación pueda considerarse

70 Manlio Mazziotti di Celso: "Parlamento. Funzioni», op. cit., p. 793.

71 Angelo Antonio Cervati: "La formazione delle leggi", op. cit., p. 160

72 También Mortati (en «Istituzioni [...]», op. cit., tomo II, p. 671) aludiría a la función de “indirizzo politico» en relación, particularmente, con las leyes de presupuestos, justificando en tal función el impedimento constitucional de que puedan ser deferidas para su aprobación por las Comisiones parlamentarias. 
reservada al Pleno, cuanto con el objetivo de dar una interpretación lata, amplia, a las previsiones del referido precepto constitucional.

Análogas han sido las reflexiones de la doctrina española, que ha puesto asimismo el acento en el relieve institucional de las materias contempladas por el Art. $75.3^{\circ}$, muy similares por cierto a la del Art. $72^{\circ} \mathrm{CI}$, y en su contenido de "indirizzo politico", ${ }^{73}$ bien que no hayan faltado quienes consideran un tanto alicorta esta limitación material al entender que debiera de haberse reservado al Pleno la aprobación de todo texto legal que contuviera normas "ad extra" directamente referibles a los ciudadanos por lo que tiene de respeto a éstos. ${ }^{74}$

II. Una cuestión que se ha suscitado entre la doctrina italiana ha sido la de si cabría sostener que junto a la "riserva di legge d'Assemblea» originaria, en cuanto basada en presupuestos objetivos vinculantes, puede identificarse otra reserva eventual y derivada, caracterizada por el hecho de que el mismo objetivo que se propone la primera (vincular el procedimiento legislativo al Pleno) vendría no abstractamente predeterminado en la norma en relación con unos supuestos materiales concretos, sino condicionado a un específico deber: la solicitud de los sujetos a que se refiere el párrafo tercero del Art. $72^{\circ}$ (el Gobierno, la décima parte de los componentes de la Cámara o la quinta parte de los miembros de la Comisión). En definitiva, esta supuesta reserva de ley de Pleno eventual y derivada tendría su encaje constitucional en la facultad constitucionalmente reconocida a las minorías parlamentarias y al Gobierno de revocar la delegación legislativa en Comisión con su mera solicitud formal de reenvío al Pleno del proyecto mientras no haya recaído aprobación definitiva del mismo.

Traversa ${ }^{75}$ a nuestro juicio muy acertadamente, se ha manifestado contrario a admitir esta reserva eventual y derivada, y ello por cuanto en tal caso no nos encontraríamos ante una auténtica reserva de un procedimiento determinado, ya que su operatividad se deja a la discrecionalidad

73 Agustín Ruiz Roblcdo: "La delegación legislativa en las Comisiones", op. cit. p. 470 .

74 Eduardo García de Enterría y Tomás-Ramón Fernández: "Curso [...]". op. cit., tomo l, p. 159.

75 Silvio Traversa: "La riserva di legge d'Assamblea" en Rivista trimestrale di Diritto Pubblico, año XX, núm. 1, cnero-marzo 1970, p. 271 y ss.; en particular, pp. 282-293. 
de algunos sujetos que, de no manifestar una precisa voluntad al respecto, convierten en inaplicable la determinación constitucional. ${ }^{76}$ Por otra parte, esta supuesta reserva derivada o eventual no se acomoda en absoluto a la función que cumple la reserva de ley de Pleno originaria, que, como antes dijimos, se explica en función de la materia que el proyecto legislativo pretende disciplinar; por el contrario, esa supuesta reserva derivada se desvincularía del dato objetivo de la materia sobre la que versa la norma, para adquirir un carácter estrictamente subjetivo, al vincularse con la solicitud formal, por una fracción de la Cámara o por el Gobierno, de examen y aprobación directa por el Pleno de un determinado proyecto de ley, independientemente de la materia sobre, la que el mismo pueda versar.

Otra cuestión vinculada con la anterior es la de si cabe ampliar por intermedio de los Reglamentos parlamentarios la competencia del Pleno y, por lo mismo, la reserva de ley de Pleno.

La Constitución italiana deja abierta de algún modo tal posibilidad al remitir a los Reglamentos de las Cámaras la determinación de los casos en que procede deferir a las Comisiones la aprobación de un proyecto de ley. Esta remisión posibilita que la norma reglamentaria pueda ampliar el ámbito material de la "riserva di legge d'Assemblea", excluyendo alguna otra materia no contemplada por la Constitución de la competencia de la comisión en sede deliberante. Así, el Reglamento de la Cámara de Diputados que antecediera al hoy vigente de 18 de febrero de 1971 (aunque modificado en varias ocasiones), en el último párrafo de su Art. $40^{\circ}$, dispuso que el procedimiento de aprobación de las leyes en comisión no se aplicaría "a los proyectos en materia tributaria». A su vez, en el vigente Reglamento del Senado de 1971, modificado en distintas ocasiones, el Art. $35^{\circ}$ exceptúa de los proyectos que pueden ser aprobados por las Comisiones en función deliberante los de conversión en ley de los decretos-leyes y aquellos otros devueltos a las Cámaras por el Presidente de la República, antes de su promulgación, a fin de que las cámaras lleven a cabo una nueva deliberación, al amparo de lo dispuesto

76 Elia, por contra, ha entendido que cabe ampliar esta "riserva di legge d'Assemblea" respecto a cualquier proyecto legislativo deferido a las Comisiones deliberantes en base a la solicitud de una minoria parlamentaria o del Gobierno. Este reenvío al Pleno propiciaría, pues, siempre a juicio de Elia, una ampliación "ex post" de la reserva de ley de Pleno. Lcopoldo Elia: «Le commissione, parlamentari italiane nel procedimento legislativo", op. cit., p. 89. 
por el Art. $74^{\circ}$ de la Constitución. Para estos proyectos, al igual que para los mencionados por el Art. $72^{\circ} \mathrm{CI}$, serán siempre obligatorias la discusión y votación en el Pleno del Senado, lo que, de alguna manera, presupone una ampliación del ámbito material de la reserva de ley de Pleno constitucionalmente establecida.

Sin embargo, entre la reserva de ley de Pleno constitucionalmente establecida y su ampliación por vía reglamentaria hay una diferencia importante que no puede dejar de destacarse: mientras la primera se haya sujeta al control de constitucionalidad por la «Corte», no sucede otro tanto respecto de la segunda. En la ya citada Sentencia de 3-9 de marzo de 1959, núm. 9, y frente a las pretensiones de quienes sostenían que todas las normas ordenadoras del procedimiento legislativo, incluso las no constitucionales, tenían relevancia a los efectos de un control de constitucionalidad formal, basado en un vicio procedimental, la «Corte" italiana excluyó este tipo de control en relación con las normas de rango infraconstitucional, particularmente las contenidas en los Reglamentos parlamentarios, reflexionando como sigue:

"Mentre il giudizio se un disigno di legge rientra fra quelli per i quali l'ultimo comma dell'art. $72^{\circ}$ Cost. esige la procedura normale di approvazione, escludendo quella decentrata, involge una questione di interpretazione di una norma della Costituzione che è di competenza della Corte costituzionale agli effetti del controllo della legittimità del procedimento di formazione di una legge, la determinazione, invece, del senso e della portata della disposizione dell'art. $40^{\circ}$ del Regolamento della Camera, che esclude la procedura decentrata per l'approvazione di "progetti in materia tributaria" riguarda una norma, sull'interpretazione della quale, essendo stata posta dalla Camera nel suo regolamento esercitando la facoltà ad essa attribuita dall'art. $72^{\circ}$ Cost. è da ritenersi decisivo l'apprezzamento della Camera" ".

Al excluir del control de constitucionalidad los «interna corporis» la "Corte" dejaba un resquicio importante en orden a lograr un auténtico y completo control de constitucionalidad de los vicios formales del procedimiento legislativo, pues, como advirtiera Barile ${ }^{78}$ todos los vicios

77 Sentencia de 3-9 de marzo del 1959, núm 9, considerato in diritto 2.

78 Paolo Barile: "Il crollo di un antico feticio (gli interna corporis) in una storica (ma insoddifacente) sentenza", op. cit., p. 241. 
formales de la ley, manifestándose como vicios del procedimiento podrían, en rigor, ser incluidos entre los vicios de los «interna corporis» parlamentarios, observación que basta por sí sola para poner en duda la validez de la tesis de la incontrolabilidad de los «interna corporis».

III. En España, también encontramos en los Reglamentos del Congreso de los Diputados y del Senado alguna ampliación de la reserva de ley de Pleno constitucionalmente establecida. Sin embargo, estas ampliaciones no responden a un intento de incrementar el ámbito material reservado a la ley de Pleno, sino más bien a la necesidad de acomodar el procedimiento legislativo a ciertas exigencias formales constitucionalizadas en otras normas de la Constitución.

El Art. $90.2^{\circ} \mathrm{CE}$ posibilita al Senado para, mediante mensaje motivado, oponer su veto o introducir enmiendas en todo proyecto de ley aprobado previamente por el Congreso del que esté conociendo la alta Cámara. El veto debe además ser aprobado por la mayoría absoluta del Senado. No cabe duda de que esta cláusula constitucional reserva al Pleno del Senado la facultad de vetar los proyectos previamente aprobados por el Congreso. En sintonía con ello, el Art. $131^{\circ}$ del Reglamento del Senado, Texto Refundido de 3 de mayo de 1994, dispone que si se presentase alguna propuesta de veto y fuese aprobada en Comisión, para su ratificación o rechazo deberá ser convocado el Pleno del Senado, no obstante lo dispuesto en el Art. $130^{\circ}$ respecto de la delegación de la competencia legislativa en las Comisiones, es decir, no obstante haber sido delegada la competencia para la aprobación del proyecto o proposición de ley en la correspondiente Comisión legislativa.

Por otro lado, el propio Art. $90.2^{\circ}$ de la Norma suprema dispone que el proyecto vetado o enmendado por el Senado «no podrá ser sometido al Rey para sanción sin que el Congreso ratifique por mayoría absoluta, en caso de veto, el texto inicial, o por mayoría simple, una vez transcurridos dos meses desde la interposición del mismo, o se pronuncie sobre las enmiendas, aceptándolas o no por mayoría simple».

En desarrollo de tal determinación, el Art. $149.2^{\circ}$ del Reglamento del Congreso de los Diputados dispone lo que sigue:

"Las Comisiones carecerán de competencia para conocer con plenitud legislativa de los proyectos o proposiciones de ley que hubieren sido vetados o enmendados por el Senado, siempre que el veto o las enmiendas hubieran sido aprobados por el Pleno de dicha Cámara». 
La doctrina se muestra de acuerdo en la contradicción de esta norma con el Art. $90.2^{\circ} \mathrm{CE}^{79}$. En efecto, su inciso final, («siempre que [...]») resulta claramente incongruente. En primer término, porque el veto no puede ser sino aprobado por el Pleno del Senado. Y en segundo lugar, porque, como dice Recoder ${ }^{80}$, tal como está redactado el precepto, pudiera incluso suceder que la aprobación final, por el Congreso se produjera en Comisión, aunque la tramitación de la primera lectura no hubiera sido delegada, si el Senado hubiera utilizado la delegación. Consiguientemente, debe interpretarse que las Comisiones del Congreso carecen de competencia para conocer con plenitud legislativa de los proyectos vetados por el Senado, pues, en primer término, el veto senatorial, sólo puede interponerse por el Pleno de la alta Cámara, y en segundo término, con independencia ya del órgano competente para interponerlo, el veto del Senado desencadena inexcusablemente un pronunciamiento en uno u otro sentido, por parte del Pleno del Congreso, que es el único órgano de la Cámara que, por mayoría absoluta o simple, según los casos, puede ratificar el texto inicialmente aprobado por el Congreso.

En cuanto a las enmiendas introducidas por el Senado, de acuerdo con el Art. $149.2^{\circ}$ del Reglamento del Congreso, cuando quien las apruebe sea el Pleno del Senado, las Comisiones carecerán de competencia para pronunciarse sobre ellas, mientras que, "a sensu contrario", hay que entender que cuando quien las apruebe sea una Comisión del Senado, la Comisión del Congreso que sea competente podrá pronunciarse sobre esas enmiendas a fin de aceptarlas o no por mayoría simple. Ello no obstante, como constata García-Escudero ${ }^{81}$, la praxis revela que es el Pleno del Congreso de los Diputados quien se pronuncia de hecho sobre las enmiendas del Senado, hayan sido o no aprobadas por el Pleno de la otra Cámara.

IV. Un problema relevante que plantea la reserva de ley de Pleno no es el de definir con exactitud el ámbito de cada una de las materias reservadas al Pleno.

79 Así, por ejemplo, Ma. Asunción García Martínez: «El procedimiento legislativo", op. cit., pp. 295-296.

80 Emilio Recoder de Casso: "Comentario al artículo 75", op. cit., p. 1168.

81 Piedad García-Escudero Márquez: «Las especialidades del procedimiento legislativo en el Senadon, op. cit., p. 501. 
Basta con atender a las respectivas normaciones constitucionales italiana y española para constatar la similitud de las materias reservadas a los respectivos Plenos de las Cámaras. Con todo, parece que la cláusula constitucional española ha sido bastante más precisa que la italiana especialmente en la primera de las materias objeto de esta reserva: los proyectos de ley "en materia constitucional» en Italia frente a la reforma constitucional en España. Es precisamente esta alusión a los proyectos legislativos "en materia constitucional" la que ha suscitado, con diferencia, mayores problemas hermenéuticos entre la doctrina italiana.

Una mayoría de tratadistas se ha inclinado por interpretar en un sentido material la referencia del Art. $72^{\circ} \mathrm{CI}$. Así, Balladore-Pallieri ${ }^{82}$ entiende que tal expresión se refiere a aquellos proyectos en materia electoral (expresamente mencionados por el propio Art. $72^{\circ}$ ), en materia de ciudadanía o en otros ámbitos materiales que pertenezcan por su naturaleza al Derecho constitucional. En un sentido sustancialmente análogo, Pierandrei ${ }^{83}$ ha rechazado una interpretación formalista de esta cláusula de modo tal que sólo las leyes de reforma de la Constitución y las demás leyes constitucionales a que se refiere el Art. $138^{\circ}$ de la norma suprema italiana tengan encaje en el ámbito material de la uriserva di legge d'Assemblea". Entender por leyes "en materia constitucional" aquellas para cuya aprobación se halla expresamente previsto el Art. $138^{\circ}$ representaría, según el citado autor, un sinsentido, por la sencilla razón de que tales leyes exigen acudir a un procedimiento especial que excluye de modo automático la aplicación del procedimiento "por Comisiones». Por otro lado, como bien advierte Pierandrei, la interpretación más amplia se halla justificada por la propia literalidad del precepto: "leyes en materia constitucional» en vez de "leyes de revisión constitucional» o de «leyes constitucionales». También Mazziotti, con apoyo en la determinación del inciso inicial del Art. $92.1^{\circ}$ del Reglamento de la Cámara de Diputados de 1971, se decanta por una interpretación análoga, incluso con abandono de la interpretación jurisprudencial de la Corte Costituzionale a la que después nos referiremos. Según el citado autor ${ }^{84}$, la interpretación «materialista» aparecería confirmada por aquella norma reglamentaria, que al impedir el procedimiento descentralizado

82 G. Balladore-Pallieri: "Diritto Costituzionale», op. cit., pp. 220-221.

83 Franco Pierandrei: "Les Commissions Législatives [...]", op. cit., pp. 569-570.

84 Manlio Mazziotti di Celso: "Parlamento. Funzioni», op. cit., p. 794. 
para los proyectos legislativos relativos a cuestiones que tuvieren una especial relevancia de orden general, implicaría que, con mayor razón aún, debieran ser excluidos de dicho procedimiento todos aquellos proyectos relativos a materia constitucional.

Esta interpretación material fue seguida por el Parlamento hasta finales de 1958, acentuándose con ello la preeminencia del procedimiento normal en perjuicio del procedimiento en comisión deliberante. Sin embargo, esta praxis parlamentaria quebraría a partir de la Ley de 24 de marzo de 1958, $\mathrm{N}^{\circ} 195$, sobre el Consejo Superior de la Magistratura, aprobada en el Senado en comisión legislativa. La "Corte Costituzionale», llamada a pronunciarse sobre esta cuestión, haría suya la tesis según la cual "materia constitucional" y "forma constitucional" son expresiones equivalentes,

En su Sentencia de 12-23 de diciembre de 1963 , N $168^{85}$, la "Corte» rechazará que la expresión del último párrafo del Art. $72^{\circ}$ «i disegni di legge in materia costituzionale» se refiera a un tipo de leyes que, teniendo forma ordinaria, no obstante, por su ámbito sustancial, sean susceptibles de ser englobadas dentro de la materia constitucional. La disposición en cuestión, bien al contrario, debe entenderse referida al Art. $138^{\circ}$ de la Constitución (que alude a las leyes de reforma de la Constitución y demás leyes constitucionales, estableciendo el procedimiento a seguir para su aprobación y reforma. De acuerdo con esta interpretación, la «Corte» entiende que el último párrafo del Art. $72^{\circ}$, en su conexión con el Art. $138^{\circ}$ viene, en definitiva, a constituir un límite expreso que opera en el sentido de excluir el procedimiento descentralizado respecto a aquellas normas a las que el Parlamento, con fines de naturaleza política, atribuya eficacia de ley constitucional. No opera dicho límite, por contra, respecto de las leyes ordinarias para las que puede utilizarse el procedimiento descentralizado.

Frente a las dos tesis, enfrentadas, la de identidad de contenido entre la cláusula del Art. $72^{\circ}$, párrafo último, y el Art. $138^{\circ}$, y la de diversidad de contenido, que posibilitaría que entraran en la categoría normativa del último párrafo del Art. $72^{\circ}$ todas aquellas leyes ordinarias que por su ámbito material vinieran referidas a la materia constitucional, la "Cor- 
te" se decanta por la primera de las tesis, la más formalista, desdeñando una interpretación material de la cláusula constitucional en cuestión.

La doctrina ha sido bastante crítica respecto a la hiperformalista interpretación de la "Corte Costituzionale». Biscaretti ${ }^{86}$, en un trabajo monográfico sobre el tema, se inclinaría de modo inequívoco por la necesidad de delinear una categoría conceptual de "leggi in materia costituzionale» distinta de las "leggi costituzionali» entendidas en sentido formal, reclamando que cuando la "Corte» fuera llamada en el futuro a afrontar de nuevo un problema análogo, tuviera el coraje de invertir su originaria y contingente opción interpretativa, adhiriéndose a la tesis de la diversidad de contenido entre las expresiones acogidas por la Constitución en los tantas veces citados arts. $72^{\circ}$ y $138^{\circ}$. Según Biscaretti ${ }^{87}$, la gran mayoría de los iuspublicistas acogería favorablemente tal cambio de interpretación jurisprudencial.

Basta con atender a las consecuencias dimanantes de la interpretación formalista de la "Corte" para comprender lo erróneo de la misma. Como advierte Cervati ${ }^{88}$ tal interpretación posibilita aprobar en Comisión, sin intervención del Pleno, leyes ordinarias que institucionalicen un órgano constitucional (como aconteció con la Ley de 24 de marzo de 1958), leyes limitativas de las libertades Constitucionalmente garantizadas y otras leyes ordinarias que de acuerdo con la Constitución puedan incidir, limitativamente, sobre el ámbito de las atribuciones constitucionales de órganos o entes. En definitiva, como dice Manzella ${ }^{89}$ la libertad de elección del procedimiento legislativo (en "commissione referente» o en "commissione deliberante») ha llegado a ser notabilísima como consecuencia de esta interpretación restrictiva de la fórmula «disegni di legge in materia costituzionale».

La Constitución española ha soslayado los problemas interpretativos suscitados en Italia al referirse en su Art. $75.3^{\circ}$ tan sólo a «la reforma constitucional», ámbito que en cualquier caso resultaría excluído de la competencia legislativa plena de las Comisiones a la vista de las previsiones del Título X de la Constitución, relativo a la reforma constitucional.

86 Paolo Biscaretti di Ruffia: "I 'disegni di legge in materia costituzionale? di cui all'art. $72^{\circ}$ comma 4 Cost.", en "Scritti in onore di Costantino Mortati”, vol. 4, Giuffrè. Milán, 1977, p. 43 y ss.: en concreto, p. 52.

87 Ibidem, pp. 61-62.

88 Angel Antonio Cervati: "La formazione delle legge", op. cit., p. 164.

89 Andrea Manzella: "Il Parlamento", op. cit., p. 318. 
Por lo demás, parece una evidencia que entender lo contrario, como se ha afirmado ${ }^{90}$, supondría una aberración constitucional.

Complementando la exclusión de la reforma constitucional de toda posible delegación legislativa en Comisión, el Art. $75.3^{\circ}$ también excluye a las leyes orgánicas cuyo ámbito material, contemplado por el Art. $81^{\circ} \mathrm{CE}$, justifica sobradamente tal exclusión (entre otras, son leyes orgánicas las relativas al desarrollo de los derechos fundamentales y de las libertades públicas, las que aprueben los Estatutos de Autonomía y el régimen electoral general [...]), no obstante lo cual, dicha exclusión vendría asimismo exigida por el Art. $81.2^{\circ} \mathrm{CE}$ al exigir la mayoría absoluta del Congreso, en una votación final sobre el conjunto del proyecto, para la aprobación, modificación o derogación de las leyes orgánicas.

Otra de las categorías normativas contempladas por la norma italiana es la relativa a las leyes de delegación legislativa, que tiene asimismo su correlato en la Constitución española, que se refiere a las leyes de bases.

La razón de reservar al Pleno las leyes de delegación legislativa es la de evitar que escape al control de cada Cámara una decisión, que puede tener graves consecuencias institucionales, como es la de apreciar la oportunidad de delegar en favor del Gobierno el ejercicio de una potestad legislativa. Cabe al efecto recordar que el Art. $76^{\circ}$ de la Constirución italiana predetermina el contenido mínimo de la ley de delegación: ésta debe especificar los principios y criterios directivos, el plazo limitado de tiempo por el que se delega y el objeto determinado para el que se delega. Más aún, la Corte Costituzionale ha tenido la oportunidad de afirmar que una simple ley de prórroga del plazo de la delegación debe ser aprobada por el Pleno de cada Cámara ${ }^{91}$.

A la vista de las previsiones constitucionales, se comprende la importancia que en el marco constitucional reviste la definición de los "principios y criterios directivos" ("principe e criteri direttivi») que han de guiar la actuación del legislador delegado, lo que, como se ha señala$\mathrm{do}^{92}$, explica esta mayor reserva sustancial en favor del legislador parla-

90 Mercedes Senén Hernández: «El Pleno de las Comisiones» (Comentario al artículo $75^{\circ}$ de la Constitución), en Oscar Alzaga Villaamil (dir.), "Comentarios a la Constitución Española de 1978", tomo VI, Cortes Generales-Editoriales de Derecho Reunidas, Madrid, 1998, p. 531 y ss.; en particular, p. 565.

91 Sentencia de la "Corte Costituzionale» de 10 de abril de 1962, núm. 32. Puede verse en "Giurisprudenza Costituzionale», 1962, p. 252 y ss.

92 Angelo Antonio Cervati: "La formazione delle leggi", op. cit., pp. 162-163. 
mentario en general y del Pleno de cada Cámara en particular, en la determinación de los principios de la legislación estatal. Por lo mismo, es evidente que sería inconstitucional una redefinición de los principios, criterios directivos u otros límites de la potestad legislativa delegada que se contuvieran en una ley aprobada en comisión.

La Constitución española, como antes se dijo, reserva al Pleno de cada Cámara no todas las leyes de delegación, sino tan sólo las leyes de bases. A tenor del Art. $82^{\circ} \mathrm{CE}$, la delegación legislativa puede otorgarse bien mediante una ley de bases, cuando su objeto sea la formación de textos articulados, bien mediante una ley ordinaria, cuando se trate de refundir varios textos legales en uno solo. El hecho de que las leyes ordinarias de delegación que autoricen la refundición de textos legales puedan, aunque quizá no deban, ser aprobadas en Comisión, a diferencia de las leyes de bases, se explica quizá por el carácter más técnico de la legislación que aquí se delega. Por el contrario, las leyes de bases son el correlato en la Constitución española de la delegación legislativa a que se refiere la Carta italiana en sus artículos $76^{\circ}$ y $77^{\circ}$, párrafo primero, por lo que lo que antes se dijo respecto de la delegación legislativa en Italia podría reiterarse ahora respecto de las leyes de bases en España. No es casual, por ejemplo, que el Art. $82.4^{\circ} \mathrm{CE}$ disponga que «las leyes de bases delimitarán con precisión el objeto y alcance de la delegación legislativa y los principios y criterios que han de seguirse en su ejercicio", fórmula claramente inspirada en la del Art. $76^{\circ}$ de la CI. Todo ello al margen ya del hecho indiscutible de que el Texto español ha sido bastante más restrictivo que el italiano a la hora de contemplar las condiciones que ha de reunir la delegación en el Ejecutivo de la potestad legislativa.

Una nueva categoría normativa que, con diferentes formulaciones, encontramos en ambos códigos constitucionales es la de los proyectos de leyes de autorización para ratificar tratados internacionales (Art. $72^{\circ}$ $\mathrm{CI}$ ), que en el Art. $75.3^{\circ} \mathrm{CE}$, más genérica y ampliamente, se formula en relación con «las cuestiones internacionales».

Pocos problemas hermenéuticos suscita la cláusula italiana, que ha de ponerse en conexión con lo establecido en el Art. $80^{\circ}$ de la propia Constitución, que enumera los tratados cuya ratificación ha de ser autorizada por las Cámaras mediante ley lógicamente reservada al Pleno.

Mayores dudas hermenéuticas suscita la referencia del Art. $75.3^{\circ} \mathrm{CE}$ a "las cuestiones internacionales". En principio, hay que entender como 
inequívoco que todos los tratados internacionales respecto de los que la prestación del consentimiento del Estado para obligarse requiera la intervención de las Cortes Generales serán reconducibles a esta materia de las cuestiones internacionales que es objeto de esta reserva de Pleno. Bien es verdad que los tratados a que alude el Art. $93^{\circ} \mathrm{CE}$ (tratados por los que se atribuya a una organización o institución internacional el ejercicio de competencias derivadas de la Constitución), al requerir su celebración de la previa autorización mediante ley orgánica, ya presuponían una reserva de Pleno. Hay que entender, por lo mismo, que son los tratados mencionados por el Art. 94.1 ${ }^{\circ} \mathrm{CE}$ los directamente afectados por la reserva al Pleno de este ámbito material de las relaciones internacionales. ${ }^{93}$

La materia objeto de reserva que ahora abordamos no se agota en la autorización para la ratificación de los tratados mencionados por el Art. $94.1^{\circ} \mathrm{CE}^{94}$, sino que debe asimismo proyectarse hacia la intervención de las Cortes Generales a que se refiere el Art. $63.3^{\circ} \mathrm{CE}$, a cuyo tenor, corresponde al Rey, previa autorización de las Cortes Generales, declarar la guerra y hacer la paz, norma que aunque en los últimos lustros haya pasado a ser casi un exotismo en la mayoría de las constituciones, no deja de estar vigente. Concordamos con el juicio de Ruiz Robledo ${ }^{95}$ cuando señala que la propia importancia de esos actos hace impensable que fueran tomados por las Comisiones; pero, por si acaso, el Art. $75.3^{\circ}$ CE lo impide.

Hemos de referirnos, finalmente, a la última de las categorías normativas sujeta a reserva de Pleno. Se trata de los proyectos de leyes de aprobación de presupuestos y cuentas, categoría del Art. $72^{\circ}$ de la Cons-

93 Los tratados que, a tenor del Art. $94.1^{\circ} \mathrm{CE}$, requieren de la previa autorización de las Cortes Generales son éstos: a) Tratados de carácter político. b) Tratados o convenios de carácter militar. c) Tratados o convenios que afecten a la integridad territorial del Estado o a los derechos y deberes fundamentales establecidos en el Título I. d) Tratados o convenios que impliquen obligaciones financieras para la Hacienda pública. e) Tratados o convenios que supongan modificación o derogación de alguna ley o exijan medidas legislativas para su ejecución.

94 Villacorta se ha manifestado partidario de una más estricta reserva de Pleno en las cuestiones internacionales, tanto respecto de Italia como de España, tesis con la que no concordamos. Luis Villacorta Mancebo: "Hacia el equilibrio de poderes", op. cit., p. 428.

95 Agustín Ruiz Robledo: «La delegación legislativa en las Comisiones», op. cit., p. 472. 
titución italiana que tiene su correlato en el Art. $75.3^{\circ} \mathrm{CE}$ en los Presupuestos Generales del Estado.

La doctrina italiana ha entendido que esta categoría proyecta su ámbito material no sólo a los presupuestos y cuentas, sino, más ampliamente, a toda ley de programación global de los gastos públicos ${ }^{97}$. Asimismo, esta reserva se extendería a toda alteración de las determinaciones básicas de los balances de previsiones. Con el paso del tiempo se ha ido dando una interpretación cada vez más rigurosa a esta categoría, frente a lo que aconteciera en los primeros momentos de desarrollo constitucional en los que, por ejemplo, el Art. $26^{\circ}$ del texto inicial del Reglamento del Senado dispuso expresamente que los proyectos legislativos que comportaran variaciones presupuestarias pudieran ser deferidos a las comisiones en función deliberante. Con todo, como constatara Elia ${ }^{97}$, algunas incertidumbres subsistían al respecto, como, por ejemplo, en relación con la convalidación de los decretos presidenciales para los cobros parciales anticipados con cargo a los fondos de reserva con la finalidad de hacer frente a los gastos imprevistos.

La norma constitucional española ha sido en este punto bastante más precisa que la italiana al delimitar un ámbito muy concreto como es el de la Ley presupuestaria a que se refiere el Art. $134^{\circ} \mathrm{CE}$. Aunque este precepto constitucional no establece ninguna específica exigencia procedimental que garantice de intervención del Pleno, parece claro, como se ha precisado ${ }^{98}$, que el margen ya de la garantía del Art. $75.3^{\circ}$ $\mathrm{CE}$, la intervención de los Plenos debía de hallarse garantizada por tratarse del acto parlamentario por excelencia: la aprobación de los Presupuestos, y asimismo, porque el Congreso y el Senado son titulares de una auténtica competencia material en el ámbito presupuestario, muy superior a la estrictamente formal de aprobación del texto legal.

V. Una última cuestión debemos de abordar en relación con la reserva de ley de Pleno. Y es la relativa al significado que la misma presenta, si es que tiene alguno, en el marco de las fuentes del derecho.

En la doctrina italiana se ha difundido en algunos sectores la tesis de que las leyes reservadas al Pleno (all'assemblea) constituirían una catego-

96 Angelo Antonio Cervati: "La formazione delle leggi», op. cit., p. 163.

97 Leopoldo Elia: "Le commissioni parlamentari italiane nel procedimento legislativo", op. cit., p. 88 .

98 Emilio Recoder de Casso: “Comentario al artículo 75", op. cit., p. 1167. 
ría normativa caracterizada, frente a otras leyes formales, por dos rasgos que podrían definirse así: a) "leggi rinforzate», en virtud del particular procedimiento prescrito obligatoriamente para su aprobación, y b) «fonti atipiche", en consideración a su inmodificabilidad por parte de leyes posteriores que no hayan sido aprobadas de acuerdo con el mismo procedimiento" ${ }^{91}$; en este tipo de fuentes, los dos aspectos, activo (eficacia abrogativa) y pasivo (resistencia a la abrogación), de la fuerza formal estarían disociados, según Crisafulli ${ }^{100}$.

Se ha hablado asimismo por otros sectores doctrinales de una "competenza innovativa maggiore" ${ }^{101}$ propia de las leyes sujetas a esta reserva, frente a las leyes aprobadas bien por el Pleno bien por las Comisiones, rasgo con el que se pretendería tan sólo mostrar un elemento de atipicidad, no obstante lo cual la doctrina ha terminado inevitablemente por plantear la cuestión en términos de jerarquía formal, esto es, de jerarquía en el marco de las fuentes del ordenamiento jurídico.

Sin embargo, como advierte Traversa ${ }^{102}$, la peculiaridad de las leyes reservadas al Pleno de no poder ser modificadas por leyes ulteriores que no hayan sido aprobadas de acuerdo con el mismo procedimiento, no puede inducir a considerar aquellas leyes como jerárquicamente superiores a otras leyes formales aprobadas en Comisión, porque si bien es cierto que la ley reservada al Pleno resiste frente a su abrogación o modificación por parte de otras leyes formales no aprobadas con idéntico procedimiento, lo cierto es que ello depende no ya de elementos formales (el hecho de que la ley primera haya sido aprobada por el Pleno y no por la Comisión), sino de elementos materiales, pues lógicamente una norma que derogue o modifique normas que disciplinen materias reservadas al Pleno también entra dentro de las exigencias del último párrafo del Art. $72^{\circ} \mathrm{CI}$ por su propio contenido material. Interpretarlo de otro modo conduciría a consecuencias absurdas, como, por ejemplo, la de

99 Vezio Crisafulli: "Gerarchia e competeza nel sistema costituzionale delle fonti”, en Rivista Trimestrale di Diritto Pubblico, año X, 1960, fasc. 4, p. 775 y ss.; en particular, p. 792. Asimismo, Vezio Crisafulli "Fonti del Diritto" (Diritto costituzionale), en "Enciclopedia del Diritto", vol. XVII, Giuffrè, Milán, 1968, p. 925 y ss.; en particular, pp. 962-966.

100 Ibidem, p. 790.

101 Sorrentino: «La Corte Costituzionale», I, p. 48 y ss., Cit. por Angelo Antonio Cervati: "La formazione delle leggi», op. cit., p. 157.

102 Silvio Traversa: "La riserva di legge d'Assemblea", op. cit., pp. $274-275$. 
entender que en aquellos supuestos en que queda a la libre discrecionalidad de las Cámaras optar por uno u otro procedimiento legislativo (aprobación en Comisión o en Pleno del proyecto legislativo), adoptada la decisión en favor del procedimiento de Pleno, toda ley ulterior en la materia habría de ser, inexcusablemente, aprobada por el Pleno, lo que entorpecería notablemente el procedimiento legislativo en contraste frontal con el espíritu y la letra del Art. $72^{\circ}$.

En definitiva, no parece muy útil, a los fines de una ajustada interpretación del último párrafo del Art. $72^{\circ} \mathrm{CI}$, entender que el mismo ampara la existencia de varios niveles de fuerza o eficacia de la ley, en el ámbito de la categoría general de las leyes ordinarias. Como dice Cervati ${ }^{103}$, no se trata de negar que las leyes aprobadas por el Pleno en base a la reserva que nos ocupa, no puedan ser sustituidas más que por una nueva ley aprobada asimismo por el Pleno, sino de observar que ésta no es más que una consecuencia del hecho de que la Constitución veda en algunos supuestos el recurso a las comisiones deliberantes, rechazando de igual forma que la necesaria aprobación plenaria del proyecto constituya el corolario de la institucionalización por parte de la Constitución de un nuevo tipo de ley ordinaria de eficacia reforzada. Dicho de otro modo, la reserva de ley de Pleno no puede reconducirse al ámbito de las fuentes del ordenamiento jurídico.

VI. En España, la problemática anteriormente suscitada debe ser resuelta en términos análogos, siendo las reflexiones precedentes, en buena medida, perfectamente extrapolables al caso español. Nos detendremos algo más en ello.

Ante todo, hay que significar que la reserva de ley de Pleno que formula el Art. $75.3^{\circ} \mathrm{CE}$ carece de trascendencia en el ámbito de las fuentes del derecho, esto es, no comporta la creación de un tipo nuevo de norma, diferenciado de las restantes. Dicho de otro modo, las leyes constitucionalmente reservadas al Pleno no tienen, en contra de lo que sostuvo Sorrentino en Italia, una mayor capacidad innovadora, o lo que es igual, una eficacia superior a la de otras leyes. Por contra, las leyes de Comisión y las leyes de Pleno, independientemente ya de que estén o no constitucionalmente reservadas al Pleno, una vez superada la fase 
integradora de eficacia a que se refiere el Art. $91^{\circ}$ de la CE, esto es, una vez sancionadas por el Rey, promulgadas y publicadas, se incorporan al ordenamiento jurídico con idéntica fuerza. Como se ha dicho ${ }^{104}$, unas y otra ocupan el mismo lugar en la jerarquía normativa y las posibles antinomias entre ellas habrán de resolverse en base a los criterios conocidos de la ley posterior que prima sobre la anterior y de la ley especial que prima sobre la general.

La regla precedente rige de modo general en las relaciones entre las leyes de Comisión y de Pleno siempre que, en el último supuesto, no vengan referidas a materias constitucionalmente reservadas al Pleno. Ello es así por cuanto que en este último caso las Cámaras carecen de la capacidad de optar entre el procedimiento legislativo ordinario o el descentralizado, imponiéndose "ex constitutione» el procedimiento ordinario a fin de garantizar, dada la trascendencia político-institucional de la materia a normar, un pronunciamiento plenario de la Cámara en cuanto que se entiende que el mismo viene rodeado de mayores garantías, como revela con perfecta nitidez la muy superior publicidad ínsita en tal procedimiento.

No ha de extrañar por ello que el quebrantamiento de ese mandato constitucional se traduzca, como dijera Ruggeri ${ }^{105}$, en la pena de la invalidez constitucional de la ley. Ello presupone que una ley constitucionalmente reservada al Pleno no puede ser modificada o derogada por una ley de Comisión, lo que otorga al primer tipo de leyes una eficacia pasiva superior, una resistencia frente a su modificación o abrogación por el segundo tipo de normas legales, las leyes de Comisión.

Admitida esa mayor fortaleza desde el punto de vista de su eficacia pasiva, es necesario precisar que de ella no cabe derivar una relación jerárquica entre ambos tipos de normas legales. No es el principio de jerarquía normativa el que debe regir su relación, sino el principio de competencia.

La doctrina italiana ha dotado de un amplio contenido al concepto de «competencia», que abarca los supuestos de producción normativa diferenciada, tanto si proviene de órganos diversos, como si se origina

104 Javier Pérez Royo: «Las fuentes del derecho», Tecnos, 4a. ed., Madrid, 1988, pp. $102-103$.

105 Antonio Ruggeri: "Gerarchia, competenza e qualità nel sistema costituzionale delle fonti normativen, Giuffrè, Milán, 1977, p. 149. 
en un solo órgano, pero por procedimientos dispares. Mortati ${ }^{106}$ ejemplifica perfectamente esta posición cuando tras vincular el principio de competencia a un criterio material, que se concreta en la identificación de la naturaleza objetiva de las relaciones que han de ser objeto de regulación, entiende que ese criterio material, puede conducir bien a fuentes diversas, como acontece en el reparto de los poderes normativos entre distintos entes territoriales, bien, en el ámbito de la misma fuente de emanación a procedimientos diferenciados.

En esta misma dirección, Crisafulli recurre al principio de competencia para las leyes constitucionalmente reservadas en Italia a las Asambleas, esto es, a los plenarios de las Cámaras en su confrontación o relación con aquellas otras aprobadas en Comisión ${ }^{107}$, y otro tanto hace Zagrebelsky ${ }^{108}$, que reconduce el fenómeno de las llamadas «leyes atípicas" (leggi atipiche), entre las que deben incluirse aquellas que, como las leyes de Pleno, se hallan dotadas de una eficacia pasiva reforzada, al criterio de la competencia.

Bien es verdad que la relación internormativa entre las leyes reservadas «ex constitutione» al Pleno y las leyes de Comisión podría reconducirse no tanto al principio de competencia cuanto al que Santamaría denomina ${ }^{109}$ principio «de procedimiento». A ello conduciría la consideración de que el concepto de competencia presupone la existencia de una pluralidad de centros o fuentes de producción normativa, lo que en modo alguno se da en el caso que nos ocupa por cuanto, como ya se señaló, el Parlamento es un órgano único de estructura compleja; por lo mismo, la delegación en Comisión ni supone que el órgano delegado ejerza una competencia propia, sino la competencia del órgano delegante, ni mucho menos entraña la conversión de la Comisión en un órgano independiente, externo y ajeno a la Cámara.

El principio de procedimiento, construido en torno a una delimitación constitucional de materias (en este caso, las expresamente contem-

106 Costantino Mortati: "Istituzioni [...]", op. cit., tomo I, 10ª ed., CEDAM, Padova, 1991, pp. 332-333.

107 Vezio Crisafulli: "Gentrhia e competenza [...]", op. cit., p. 805.

108 Gustavo Zagrebelsky: «Manuale di Diritto Costituzionalle», vol. I (Il sistema delle fonti del Diritto), UTET, ristampa, Torino, 1994, p. 64.

109 Juan Alfonso Santamaría Pastor: “Fundamentos [...]", op. cit., tomo I, pp. 320-322. 
pladas por el Art. $75.3^{\circ} \mathrm{CE}$ ), vendría a diferenciar los dos tipos de normas legales por el distinto procedimiento legislativo a seguir en cada caso, dada la exigencia Constitucional de exclusión del procedimiento descentralizado respecto de las materias enunciadas por el Art. 75.3. En esta dirección, Musacchia ${ }^{110}$ significa que el reforzamiento de una fuente como la "legge d'Assemblea» del último párrafo del Art. $72^{\circ} \mathrm{CI}$ salvaguarda una determinada estructura procedimental.

En cualquier caso, el hecho de que los efectos de este principio ofrezcan una notable semejanza con los dimanantes del principio de competencia y la posibilidad, antes señalada, de reconducir a este último principio el supuesto de disparidad procedimental en la elaboración de las normas, aunque éstas provengan de un mismo órgano, nos conduce a optar por el principio de competencia como criterio delimitador de las relaciones entre las leyes constitucionalmente reservadas al Pleno y las leyes de Comisión, sin que de ello deban desprenderse consecuencias en el plano de la jerarquía normativa, consecuencias que, por ejemplo, extrae Crisafulli ${ }^{111}$, pero que, a nuestro juicio, no entrañan sino un elemento de confusión.

\section{La facultad de avocación del Pleno}

I. El Art. $75.2^{\circ} \mathrm{CE}$ faculta al Pleno de cada Cámara para recabar en cualquier momento el debate y votación de cualquier proyecto o proposición de ley que haya sido objeto de delegación legislativa a una Comisión. La norma difiere sensiblemente de la equivalente cláusula italiana que prevé que mientras no haya recaído aprobación definitiva del proyecto, éste podrá ser reenviado al Pleno de la Cámara si el Gobierno, la décima parte de los componentes de la Cámara o la quinta parte de los de la Comisión reclamen que sea discutido y votado por la propia Cá-

110 Giuseppe Musacchia: «Gerarchia e Teoria delle norme sulla produzione giuridica nel sistema costituzionale delle fonti), en Rivista Trimestrale di Diritto Pubblico, año XX, núm 1, enero-marzo 1970, p. 172 y ss.; en concreto, p. 188.

1 i 1 A juicio de Crisafulli, de las "leggi di Assemblea" y de otras leyes reforzadas parece desprenderse un elemento de superioridad jerárquica respecto de las restantes leyes formales en razón de ese "plus" de competencia que viene a añadirse a la fuerza creadora de derecho común a las restantes fuentes del ordenamiento. Vezio Crisafulli: "Gerarchia e competenza [...]", op. cit., p. 806. 
mara o bien que sea sometido a la aprobación final de ésta únicamente con declaraciones de voto.

Nos hallamos ante una suerte de cláusula de garantía con la que se trata de posibilitar que el Pleno de una Cámara pueda en todo momento anterior a la aprobación del proyecto en Comisión pronunciarse sobre el mismo en sintonía con la que, por lo menos en un plano teórico, debe ser considerada como la regla general de ejercicio de la función legislativa: ésta debe ejercerse por la totalidad de los miembros de la Cámara, pues, como dice Martines $^{112}$, así lo requiere el sistema constitucional.

II. El significado último de esta garantía difiere notablemente, como antes señalamos. La Constitución italiana la contempla, inequívocamente, como una garantía de las minorías parlamentarias y también del Gobierno, aunque ello encuentre una menor justificación, ${ }^{113}$ pues parece lógico entender que el Gobierno contará con el respaldo de la mayoría parlamentaria y que sin el beneplácito de ésta no resulta previsible que el Presidente de la Cámara proponga a la misma la asignación de un proyecto a una Comisión en régimen de competencia legislativa plena, y si, pese a ello, la propuesta se realiza, no es probable que salga adelante.

Es en relación con las minorías parlamentarias como cobra su plena significación esta garantía. ${ }^{114}$ Las minorías, y qué duda cabe que también el gobierno, pueden considerar políticamente conveniente la aprobación de una ley con la solemnidad de la plena publicidad, que sólo otorgan las sesiones plenarias, y con las demás garantías que encierra el procedimiento legislativo ordinario. Como advierte Mazziotti ${ }^{115}$, es evidente que para las minorías parlamentarias el respeto de estas garantías, particularmente de la atinente a la publicidad de las sesiones, puede revestir una particular relevancia.

112 Temístocle Martines: “Diritto Costituzionale», op. cit., p. 341.

113 Mazziotti cree que esta referencia al Gobierno por parte de la Constitución sólo se explica como un eco, una inercia derivada de la Ley de 1939 en la que se halla el origen de la institución. Manlio Mazziotti di Celso: "Parlamento. Funzioni" (Diritto costituzionale), op. cit., p. 793.

114 Es innecesario subrayar, dice Pierandrei, que estas disposiciones pretenden, desde el punto de vista político, proteger a las minorías. Franco Pierandrei: "Les Commissions Législatives [...]", op. cit., p. 571.

115 Manlio Mazziotti di Celso: "Parlamento. Funzioni" (Diritto costituzionalle), op. cit., p. 793. 
Esta garantía presenta, sin embargo, una paradoja, destacada por la doctrina ya desde los primeros momentos de vigencia de la Constitución: lo infrecuente del reenvío del proyecto de la Comisión al Pleno. En 1954, Goguel ${ }^{116}$ ya se hacía eco del escasísimo número de casos en los que la oposición parlamentaria había utilizado la facultad de obstrucción que le otorgaba el párrafo tercero del Art. $75^{\circ} \mathrm{CI}$, rasgo también constatable respecto del Gobierno, lo que, para el propio autor, era una prueba inequívoca de que el procedimiento legislativo descentralizado no colocaba al Ejecutivo, con vistas al debate legislativo, en peor posición que el procedimiento legislativo ordinario y, por lo mismo, con debate en el plenario. Esta pauta se ha mantenido con el transcurso del tiempo. Y así, Martines, en 1994, ha podido constatar ${ }^{117}$ que el gobierno y las minorías parlamentarias rara vez han requerido el reenvío del proyecto al Pleno, prefiriendo, por el contrario, que el procedimiento se desarrollase y agotase en Comisión. Por su lado, Mortati ${ }^{118}$ ha enjuiciado muy críticamente esta circunstancia al constatar que el Gobierno no ha utilizado más que rarísimamente su facultad de instar el reenvío del proyecto al Pleno, habiendo de este modo abdicado vergonzosamente del ejercicio de su función de dirección y coordinación de la actividad legislativa, a través de la cual, debe realizar la unidad del "indirizzo politico" de la que es responsable. No distinta, como antes dijimos, ha sido la actuación de la oposición parlamentaria, que se ha inhibido en el ejercicio de su facultad de reclamar el reenvío de un proyecto legislativo al "plenum" para su aprobación por el mismo, actuación que es a menudo tributaria de acuerdos más o menos subterráneos entre mayoría y minoría, realizados a expensas del interés general y susceptibles de perjudicar el siempre conveniente armónico desarrollo de la dirección política gubernamental. Si a todo ello se añade la deficiente calidad técnica de las leyes, se tiene, según Mortati ${ }^{119}$, un diseño exacto del déficit de funcionalidad del Parlamento italiano en el delicado ámbito de la formación de las normas reguladoras de las relaciones sociales.

116 François Goguel: "La procédure italienne de vote des lois par les commissions", en Revue Française de Science Politique, vol. IV, 1954 (octubre-diciembre), núm 4, p. 836 y ss.; en concreto, p. 840.

117 Temístocle Martines: "Diritto Costituzionale», op. cit., p. 340.

118 Costatino Mortati: "Instituzioni [...]", tomo II, op. cit., p. 748.

119 Ibidem. 
Señalemos, por último, que la solicitud de reenvío de un proyecto al Pleno se considera formalizada si es suscrita por el número de firmas constitucionalmente exigido, caso de que la iniciativa parta de los parlamentarios; si la misma tiene su origen en el gobierno, cabe señalar que la práctica parlamentaria ha admitido las propuestas provenientes de los Subsecretarios, aunque éstos no integren formalmente el Gobierno. De igual forma, la praxis ha venido a decantar la posibilidad de que la propuesta de reenvío al Pleno sea adelantada oralmente, a salvo una ulterior confirmación escrita del Presidente del Consejo de Ministros.

Innecesario es precisar, a la vista de la previsión constitucional, que basta con formalizar la solicitud de reenvío de un proyecto de la Comisión al Pleno por quien esté legitimado para ello para que, sin otro requisito se produzca tal reenvío. El Art. $92.4^{\circ}$ del Reglamento de la Cámara de Diputados, de 18 de febrero de 1971, aunque modificado con posterioridad en varias ocasiones, es taxativo al respecto: "El proyecto de ley -prescribe- se devolverá al Pleno si el Gobierno, un décimo de los diputados o un quinto de la Comisión así lo piden».

III. La Constitución española, como antes avanzamos, ha seguido una óptica diferente a la italiana. El Art. $75.2^{\circ}$, en efecto, faculta al Pleno para recabar el debate y votación de cualquier proyecto o proposición de ley que haya sido objeto de delegación en las Comisiones. No son, pues, las minorías parlamentarias las habilitadas para desencadenar este reenvío del proyecto al Pleno, ni mucho menos el Gobierno. Más aún, las minorías, al margen ya de la posibilidad de que disponen de instar un pronunciamiento del plenario en torno a la avocación con ocasión de la celebración de la sesión plenaria en que se proceda a un debate de totalidad sobre un proyecto (pertinente, a tenor del Art. $112^{\circ}$ del Reglamento del Congreso de los Diputados, siempre que se hubieren presentado enmiendas de totalidad) o de aquella otra sesión plenaria encaminada a la toma en consideración de una proposición de ley, carecen de toda capacidad de iniciativa, esto es, de instar un pronuncianiento del «plenum» sobre la avocación, pues fuera de los dos supuestos antes mencionados, a tenor del Art. 149.1 ${ }^{\circ}$ del Reglamento del Congreso (en adelante RCD), sólo la mesa del Congreso, oída la Junta de Portavoces, puede someter a votación del Pleno (que se ha de realizar sin debate previo) la propuesta de avocación.

Esta fórmula reglamentaria contrasta con la acogida por el Art. $102^{\circ}$ del Reglamento provisional del Congreso de los Diputados de 1977 , 
que tras facultar a la Mesa de la Cámara para decidir que la Comisión encargada de dictaminar un texto legislativo lo hiciere en plenitud de poder legislativo, habilitaba a las minorías parlamentarias (dos Grupos Parlamentarios o cincuenta diputados) para, expresando un parecer contrario a la delegación legislativa en el plazo de tres días contados a partir de la publicación del acuerdo de delegación, desencadenar la intervención del Pleno para decidir al respecto.

También contrasta la normación del Reglamento de la Cámara baja con la acogida por el Art. $130.2^{\circ}$ del Reglamento del Senado (en adelante RS), Texto Refundido de 3 de mayo de 1994. A tenor del mismo, el Pleno del Senado puede decidir sobre la avocación, a propuesta de la Mesa, oída la Junta de Portavoces, de un Grupo Parlamentario o de veinticinco senadores, norma evidentemente mucho más respetuosa hacia las minorías.

A la vista de la normación expuesta, es clara la diferente filosofía que inspira a la norma constitucional italiana y a la española. En Italia, el reenvío al Pleno se concibe como una garantía de las minorías parlamentarias, incluso de las minorías presentes en la Comisión en función deliberante, pues la quinta parte de sus miembros puede desencadenar si así lo entienden oportuno, el reenvío del texto legislativo al plenario. En España, es el Pleno el único que puede avocar, siendo absolutamente ignoradas las minorías por el Reglamento del Congreso, en lo que hace a la cuestión que nos preocupa, y disponiendo en el del Senado tan sólo de una facultad de instar el pronunciamiento del Pleno.

Se ha dicho ${ }^{120}$, y es cierto, que la regulación española es más congruente con la figura de la delegación, porque asegura la prevalencia de la voluntad de la Cámara en todas las hipótesis, mientras que en Italia puede existir un Pleno con voluntad mayoritaria de delegar, cuya decisión es revocada por una minoría de aquél. Algún sector de la doctrina italiana ${ }^{121}$ ha utilizado incluso como argumento de rechazo a la calificación como "delegación» del título jurídico en que se asienta la competencia de la Comisión, el hecho de que el reenvío del texto de la Comisión al Pleno pueda ser provocado no sólo por la décima parte de los integrantes de la Cámara, sino también por la quinta parte de los miembros de la propia Comisión deliberante y, por último, por el mismo 
gobierno. En los dos últimos supuestos, al menos, es obvio que la autoridad "revocante» no coincide con la autoridad "delegante", titular de la potestad legislativa.

Ahora bien, que ello sea así, a nuestro juicio, no comporta necesariamente una valoración más positiva de nuestra regulación, a diferencia de lo que algún sector de nuestra doctrina entiende ${ }^{122}$ por cuanto la razón de ser última de la avocación no es tanto salvaguardar la voluntad de la Cámara en torno al diseño de un determinado proyecto legislativo, pues es obvio que tal voluntad se encuentra asimismo garantizada con el procedimiento en Comisión, en cuanto que al hallarse compuestas las Comisiones de modo tal que reflejen la proporcionalidad de los distintos Grupos parlamentarios, la mayoría de la Cámara tendrá su reflejo en la Comisión y podrá ver plasmada, también en las leyes de Comisión, como no podría ser de otra manera, su voluntad. La auténtica "ratio» la de la avocación reside en posibilitar, en un determinado momento, una tramitación del proyecto legislativo en cuestión rodeada de todas las garantías procedimentales que ofrece el procedimiento legislativo ordinario, y a tal efecto debiera de ser determinante la voluntad de las minorías parlamentarias, incluso cuando se enfrente a una mayoría contraria a la avocación. Ciertamente, las minorías podrán utilizar el reenvío de un proyecto al Pleno con una finalidad básicamente obstruccionista; no cabe descartar esta hipótesis, pero ello no debe ser en modo alguno un argumento conducente a privarles de tal facultad. Más aún, se integra en la propia lógica de la vida y el debate parlamentarios la actuación obstruccionista de la oposición. De ahí que nos parezca mucho más adecuada al fin pretendido o que debiera en teoría perseguirse con la avocación, la norma constitucional italiana que la española.

IV. El párrafo tercero del Art. $72^{\circ}$ de la $\mathrm{CI}$ abre una doble posibilidad a los titulares de la facultad de instar, con efecto vinculante, el reenvío del proyecto al plenario: de un lado, requerir que el texto sea discutido y votado por el Pleno, o, lo que es igual, que se acomode en su tramitación parlamentaria al procedimiento legislativo común u ordinario, y de otro, solicitar que sea sometido a la aprobación final del plenario únicamente con declaraciones de voto, lo que entraña que el debate del articulado del proyecto se desarrolla en Comisión. En el primer caso, la

122 Luis Villacorta Mancebo: «Hacia el equilibrio de poderes», op. cit., p. 431 
competencia de la Comisión se conoce como «in sede referente»; en el segundo, como «in sede redigente». En este segundo supuesto, es evidente que la Comisión continuará ejerciendo una función deliberante en relación con el articulado del texto legislativo, de forma análoga a como lo haría en el procedimiento descentralizado, reservándose al plenario tan sólo la aprobación final. Sobre la base de tal previsión constitucional, el Reglamento de la Cámara de Diputados (Art. 96\%) y el Reglamento del Senado (Art. $36^{\circ}$ ) configuran como procedimiento especial el llamado del examen (por la Comisión) en función redactora («in sede redigente»), supuesto en el que, como apostilla la doctrina ${ }^{123}$, permanecen las garantías constitucionalmente previstas con relación a los procedimientos especiales, esto es, la reserva de ley de Pleno y la facultad atribuida al Gobierno y a las minorías parlamentarias de requerir con carácter vinculante el retorno al procedimiento legislativo normal.

Esta doble opción es reveladora, por lo menos teóricamente, de la flexibilidad subyacente en la normación constitucional italiana, elasticidad de la que, como significa Elia ${ }^{124}$, constituye otro buen ejemplo la posibilidad de revocar la solicitud de reenvío al Pleno hasta tanto no se haya iniciado la discusión plenaria del proyecto. ${ }^{125}$ En la misma dirección, Traversa ${ }^{126}$ cree que no puede existir duda acerca de la admisibilidad de la facultad de retirada de la solicitud de reenvío al Pleno del proyecto. En general, la doctrina es concordante en este punto en ausencia de una específica norma que lo prevea, a condición de que se halle prevista la correlativa facultad de plantear positivamente la solicitud. ${ }^{127}$

123 Angelo Antonio Cervati: "La formazione delli legge», op.cit., p. 153.

124 Leopoldo Elia: "Le commissione parlamentari [...]", op. cit., p. 94.

125 A este respecto, Mohrhoff entiende como válida la retirada de algunas de las firmas constitucionalmente requeridas para la formalización de la solicitud vinculante de reenvio del proyecto al Pleno, supuesto en el que tal solicitud se convertirá en inoperante al no reunir el número suficiente de firmas. Federico Mohrhoff, "Giurisprudenza parlamentare", Roma, 1950, p. 280. Cit. por Leopoldo Elia: "Le commissione parlamentari [...]", op. cit., p. 94.

126 Silvio Traversa: "La riserva di legge d'Assemblea", op. cit., pp. 288-289 y p. 289, nota 28.

127 Análoga es la posición de Sandulli en relación a la retirada de la iniciativa legislativa, postura que puede extrapolarse al caso que nos ocupa. Aldo M. Sandulli: "Legge (Diritto costituzionale), en "Novissimo Digesto italiano" (diretto da Antonio Azara e Ernesto Eula), tomo IX, $3^{a}$. ed., UTET, Torino, 1965, p. 630 y ss.; en concreto, p. 638. 
La flexibilidad de la normación Constitucional italiana se echa de menos en el texto fundamental español, cuyo Art. $75.2^{\circ}$ no contempla la doble posibilidad prevista por la Carta italiana en cuanto al reenvío al Pleno del proyecto legislativo. Por contra, el tenor del precepto español es inequívoco: el Pleno puede recabar el debate y votación de cualquier proyecto o proposición de ley. Quiere ello decir que la avocación no admite matices, sino que, lisa y llanamente, presupone el retorno del proyecto al proceso secuencial del procedimiento legislativo común u ordinario (así lo prevé específicamente el Art. $130.2^{\circ} \mathrm{RS}$ ), y es tal circunstancia la que, a nuestro juicio, con vulneración de las previsiones constitucionales, como veremos más adelante, condiciona los momentos en los que el Reglamento de la Cámara baja (que no el del Senado) contempla la posibilidad de la avocación.

Tampoco en el ordenamiento español, como es obvio si se advierte que es el Pleno el único legitimado para acordar la avocación, tiene sentido hablar de la posibilidad de revocar una solicitud de reenvío de un proyecto al Pleno.

V. Una cuestión relevante en orden a calibrar la eficacia real de la garantía de avocación por el Pleno es la relativa al momento en que puede producirse la avocación.

La Constitución italiana señala al respecto que el reenvío del proyecto al Pleno podrá tener lugar «mientras no haya recaído aprobación definitiva" ("fino al momento della sua approvazione definitiva"). A su vez, el Reglamento de la Cámara de Diputados (Art. 92.5 ) señala como momento delimitador de la autoridad a la que ha de ser dirigida la solicitud de devolución al Pleno del proyecto, la inclusión del proyecto en el orden del día de la Comisión: con anterioridad a ese momento la solicitud debe dirigirse al Presidente de la Cámara; con posterioridad al mismo, al Presidente de la Comisión. Nada precisa, sin embargo, el citado Reglamento en torno al momento constitucionalmente previsto, a diferencia de la norma reglamentaria del Senado, cuyo Art. $35.2^{\circ}$ alude específicamente a "mientras no llegue el momento de la votación final", para precisar también que con anterioridad al inicio de la discusión la solicitud se ha de dirigir al Presidente del Senado. Abierta la discusión, al Presidente de la Comisión.

Formalizada la solicitud vinculante de reenvío al Pleno, el proyecto habrá de ser de inmediato remitido al mismo. Bien es verdad que cuan- 
do la devolución del proyecto se haga a los solos efectos de que sea sometido a la aprobación final del "plenum" únicamente con declaraciones de voto, tal devolución sólo podrá disponerse tras proceder la Comisión a la formulación definitiva del texto legislativo y a la aprobación de cada uno de sus artículos.

La Constitución española, en forma semejante a la italiana, ha contemplado con notable amplitud el momento en el que puede producirse la avocación «el Pleno (dice el Art. $75.2^{\circ}$ ) podrá [...] recabar en cualquier momento el debate y votación de cualquier proyectom. Ello no obstante, el Reglamento del Congreso ha alterado muy significativamente $y$, por lo mismo, en forma inequívocamente contrapuesta al mandato constitucional, la previsión de la Norma suprema, lo que, por contra, no ha sucedido con el Reglamento del Senado.

En coherencia con el Art. $75.2^{\circ} \mathrm{CE}$, el Art. $130.2^{\circ} \mathrm{RS}$ dispone que: «el Pleno de la Cámara [...] podrá decidir en cualquier momento la observancia del procedimiento ordinario». Por el contrario, el Art. 149.1 RCD contempla dos momentos diferentes para la formalización de la avocación, delimitando por consiguiente de un modo restrictivo la determinación constitucional: respecto de los proyectos en que sea pertinente el debate de totalidad (lo que acontece, como ya se señaló, cuando se presente una enmienda de totalidad, a tenor de lo dispuesto por el Art. $112^{\circ}$ del propio Reglamento) y respecto, asimismo, de las proposiciones de ley, la avocación deberá ser acordada, en su caso, en la sesión plenaria en que tenga lugar el debate de totalidad del proyecto o el debate de toma en consideración de la proposición. En los demás casos, la avocación habrá de acordarse «antes de iniciarse el debate en Comisión».

La plena comprensión de las anteriores previsiones reglamentarias exige tener presente otra norma del Reglamento de la Cámara baja de más que dudoso encaje constitucional: el Art. $148.1^{\circ}$ por cuya virtud, "el acuerdo del Pleno por el que se delega la competencia legislativa plena en las Comisiones, se presumirá para todos los proyectos y proposiciones de ley que sean constitucionalmente delegablesm. Esta presunción de delegación transforma lo que, por mor de la Constitución, debiera ser un acuerdo potestativo del Pleno en favor de la delegación, en cuyo defecto no debería de producirse la misma, en un acuerdo avocatorio del propio pleno en cuya ausencia, por la presunción en favor de la universal delegación de todos los proyectos y proposiciones constitucionalmente delegables, quedará marginado del trámite de deliberación y 
votación final del texto legislativo. Se explica así que el Art. $149.1^{\circ} \mathrm{RCD}$ exija de modo inexcusable un acuerdo formal del plenario de la Cámara para que ésta, en sesión plenaria, pueda deliberar y realizar la votación final del proyecto. Sin ese acuerdo expreso, el texto en cuestión se entenderá de la competencia legislativa plena de la Comisión correspondiente. Esta discutibilísima fórmula, que convierte en regla general lo que no debiera ser sino una excepción puntual, contrasta con la solución acuñada por el Art. $130^{\circ}$ del Reglamento del Senado, que es justamente la contraria.

Retornando a las previsiones reglamentarias acerca del tiempo o momento de la avocación, cabe decir que la doctrina se ha mostrado prácticamente unánime en la crítica a la determinación del Art. 149.1 RCD, juzgada, asimismo de modo general, como contraria a la Constitución ${ }^{128}$. Quizás sea Recoder ${ }^{129}$ uno de los pocos autores que no ve excesiva la limitación temporal, reglamentariamente establecida, e incluso cabe entender, según el mismo autor, que es razonable situar en momentos procesalmente idóneos el ejercicio de la potestad de recabar el conocimiento, si bien admite la persistencia de la duda sobre si es lo que el constituyente quiso.

La praxis parlamentaria parece haber modulado un tanto la aplicación de las normas más dudosamente conformes con los mandatos constitucionales ${ }^{130}$. Con todo, no deja de ser significativo que las proposiciones de Reforma del Reglamento del Congreso modifiquen de modo radical el sentido del actual Art. $149^{\circ}$. Así, por poner un ejemplo, en la Proposición de Reforma publicada el 28 de mayo de $1992^{131}$, en el Art.

128 Este es el caso, entre otros, de Ramón Punset (en «La fase central del procedimiento legislativo", en Revista Española de Derecho Constitucional núm. 14, mayo-agosto 1985, p. 111 y ss.; en concreto, p. 130), Agustín Ruiz Robledo (en «La delegación legislativa en las Comisiones», op. cit., p. 475), Fernando Santaolalla López (en su "Derecho Parlamentario Español", Editora Nacional, Madrid, 1984, p. 238), Ma. Asunción García Martínez (en "El procedimiento legislativo», op. cit., p. 295) y Piedad GarcíaEscudero Márques (en "Las especialidades del procedimiento legislativo en el Senado", en el colectivo, "el Procedimiento Legislativo. 1994». -V Jornadas Derecho Parlamentario-, Congreso de los Diputados, Madrid, 1997, p. 481 y ss.; en particular, p. 501).

129 Emilio Recoder de Casso: “Comentario al artículo 75\% " op. cit., p. 1167.

130 En tal sentido se manifestaba Paniagua en 1986. Juan Luis Paniagua Soto: «El sistema de comisiones [...]", op. cit., pp. 137-138.

131 Boletín Oficial de las Cortes Generales, IV Legislatura, serie B, núm. 140-1, 28 de mayo de 1992. 
$160^{\circ}$ (equivalente al actual Art. $149^{\circ}$ ), en su apartado tercero, posibilitaba que la avocación pudiera tener lugar en cualquier momento anterior a la finalización del debate en comisión. A ello se unía la supresión de la presunción de la delegación, que había de acordarse de modo expreso y particularizado para cada proyecto o proposición, debiendo someter el Presidente del Congreso a la votación de la Cámara, sin deliberación previa alguna, el acuerdo de delegación.

VI. Hemos de referirnos, en último término, a la existencia de algunos supuestos en los que puede hablarse, como advierte Mazziotti ${ }^{132}$, de un reenvío automático de un proyecto al Pleno. Tal acontece en Italia en los dos casos a que alude el Art. $93^{\circ}$ del Reglamento de la Cámara de Diputados: el primero, cuando la Comisión competente, actuando con plena competencia legislativa, no acepte el parecer de la Comisión de Presupuestos y Programación o de la Comisión de Asuntos Constitucionales, debiendo éstas pronunciarse, bien porque el proyecto en cuestión implique mayores gastos o una disminución de los ingresos, bien porque requiera de un examen en relación a los aspectos atinentes a su legitimidad constitucional, o en los referentes a la función pública, en cuyo caso, el proyecto se habrá de enviar simultáneamente a la Comisión competente y, para la emisión de un dictamen consultivo, a la Comisión de Presupuestos y Programación o a la Comisión de Asuntos Constitucionales, respectivamente. Pues bien, insistiendo estas dos últimas Comisiones en su dictamen se habrá de producir el reenvío automático del proyecto al Pleno. El segundo caso viene dado por el hecho de que se produzca un conflicto de competencia entre la Comisión que conoce del proyecto con plena competencia legislativa y otra Comisión que afirma también su propia competencia directa sobre el mismo proyecto o sobre alguna de sus partes.

Sustancialmente análoga es la incidencia de los dictámenes obligatorios de las Comisiones permanentes de Programación económica, Presupuestos y participaciones estatales y de Asuntos Constitucionales del Senado, sobre el conocimiento de un proyecto legislativo por una Comisión con competencia legislativa plena, tal, y como determina el Art. $40^{\circ}$ apartados cuarto y quinto, del Reglamento del Senado italiano. 
También en España puede identificarse algún supuesto de avocación automática en relación con el Senado. Respecto de esta Cámara, el Art. $131^{\circ}$, de su Reglamento acoge un supuesto de esta naturaleza cuando dispone que, no obstante la actuación de una Comisión con competencia legislativa plena si se presentase alguna propuesta de veto y fuese aprobada en Comisión, para su ratificación o rechazo deberá ser convocado el Pleno del Senado. Aunque un sector de la doctrina entiende ${ }^{133}$ que en este caso nada obsta para que se mantenga la delegación en la Comisión respecto de la tramitación restante, es obvio que la intervención del Pleno, aún cuando se circunscribiere a la propuesta de veto, implica una revocación de la delegación y, por lo mismo, una quiebra del proceso descentralizado que, además se produce automáticamente, por imperativo de la norma reglamentaria.

Bien es verdad que este reenvío automático del proyecto al Pleno es deudor de la ya comentada reserva de ley de Pleno que establece el Art. $90.2^{\circ}$ de la Constitución en relación con aquellos proyectos de ley que, independientemente de la materia sobre la que versaren, fueren objeto de un veto por parte del Senado, pues sólo el Pleno puede, por la mayoría absoluta de sus integrantes, formalizar el veto.

Otro supuesto de avocación automática se encontraba en el Art. 88.3 del texto inicial del Reglamento del Congreso, norma hoy inexistente tras ser derogada en la reforma del citado Reglamento aprobada el 23 de septiembre de 1993. A tenor de la misma, en los procedimientos legislativos en los que una Comisión actuara con competencia plena, cuando se produjera por tres veces consecutivas empate en una votación, el mismo sería dirimido sometiendo la cuestión a la decisión del Pleno. Como se señalara por la doctrina ${ }^{134}$, la norma reglamentaria se hallaba en una especie de frontera entre una facultad de remisión de las Comisiones en casos extremos, y una especie de avocación automática presunta en favor del Pleno, establecida por éste con carácter general por intermedio de su propio Reglamento, para los supuestos en que concurriera la circunstancia descrita.

Tras la supresión del citado Art. $88.3^{\circ} \mathrm{RCD}$, el empate a votos tras la tercera votación en una Comisión con competencia legislativa plena deberá dilucidarse de conformidad con las reglas generales fijadas por 
los dos primeros apartados del Art. $88^{\circ}$ siendo de recordar ahora que el Art. $88.2^{\circ}$ dispone que en las votaciones en Comisión se entenderá que no existe empate cuando la igualdad de votos, siendo idéntico el sentido en el que hubieren votado todos los miembros de la Comisión pertenecientes a un mismo Grupo parlamentario, pudiera dirimirse ponderando el número de votos con que cada Grupo cuente en el Pleno. 